Article

\title{
A Systematic Review of Coastal Vulnerability Mapping
}

\author{
Anamaria Bukvic ${ }^{1, *(\mathbb{D}}$, Guillaume Rohat ${ }^{2}$, Alex Apotsos ${ }^{3}$ and Alex de Sherbinin ${ }^{4}(\mathbb{D}$ \\ 1 Department of Geography, Center for Coastal Studies, Virginia Polytechnic Institute and State University, \\ Blacksburg, VA 24061, USA \\ 2 Institute of Environmental Sciences, University of Geneva, 1205 Geneva, Switzerland; \\ Guillaume.Rohat@unige.ch \\ 3 Department of Geosciences, Williams College, Williamstown, MA 01267, USA; aa13@williams.edu \\ 4 Center for International Earth Science Information Network, The Earth Institute at Columbia University, \\ Palisades, NY 10025, USA; adesherbinin@ciesin.columbia.edu \\ * Correspondence: ana.bukvic@vt.edu; Tel.: +1-540-231-2941
}

Received: 17 February 2020; Accepted: 24 March 2020; Published: 2 April 2020

\begin{abstract}
Coastal areas worldwide represent an aggregation of population and assets of growing economic, geopolitical, and sociocultural significance, yet their functions are increasingly challenged by worsening coastal hazards. Vulnerability assessments have been recognized as one way we can better understand which geographic areas and segments of society are more susceptible to adverse impacts from different stressors or hazards. The aims of this paper are to evaluate the state of coastal vulnerability assessment mapping efforts and to identify opportunities for advancement and refinement that will lead to more cohesive, impactful, and policy-relevant coastal vulnerability studies. We conducted a systematic review of the literature that addresses physical and social vulnerability to coastal hazards and contains corresponding mapping products. The content was analyzed for the scale of analysis, location, disciplinary focus, conceptual framework, metrics used, methodological approach, data sources, mapping output, and policy relevance. Results showed that most Coastal Vulnerability Mapping Assessments (CVMAs) are conducted at the local level using a range of methodologies, often with limited inclusion of social considerations and limited discussion of policy relevance. Based on our analysis, we provide seven recommendations for the advancement of this field that would improve CVMAs' methodological rigor, policy relevance, and alignment with other vulnerability assessment paradigms.
\end{abstract}

Keywords: vulnerability; coastal; mapping; exposure; sensitivity; adaptation; sea level rise; storm surge; coastal flooding

\section{Introduction}

Depending on one's definition of the coastal zone, the population living in it ranges from 323 million at 0-5 m elevation above mean sea level (AMSL), to 1.1 billion at 0-20 m AMSL, to 2.5 billion people living within $100 \mathrm{~km}$ of the coast [1,2]. Coastal populations are growing rapidly and are projected to continue to grow faster than inland areas [3-9]. This growing population is accompanied by a significant increase in coastal development, a trend that is likely to continue for the foreseeable future [5]. Two out of five metropolitan areas with a total population of more than 100,000 globally are located on the coast, mostly in response to global trade growth centered around international ports $[10,11]$. The total population exposed to coastal flooding could increase 3-fold by the 2070s due to the combined effects of sea level rise, land subsidence, population growth, and urbanization [12]. At the same time, coastal areas experience significant hazards (e.g., hurricanes and tsunamis), and 
are expected to experience more intense and frequent tropical storms [13-17], sea level rise [18,19], and worsening nuisance flooding caused by a combination of the sea level rise, high tides, and heavy rainfall [20-22]. Recent research suggests that economic assets exposed to flooding from a once-in-a-century flood event are expected to increase by $200 \%$ by 2050 [23].

Over the past few decades, coastal hazards have had significant impacts on coastal communities. For example, the United States experienced three hurricane disasters that caused more than $\$ 50$ billion in damages in 2017 [24], while tsunamis resulted in hundreds of thousands of deaths (e.g., the 2004 Indian Ocean Tsunami) and billions of dollars in damage (e.g., 2011 Tohoku tsunami). While the immediate impacts of these events are often obvious, the long-term impacts and the feasibility of full recovery after such major events is still unclear. Some studies suggest that national incomes do not recover to their predisaster average for more than 20 years [25]. Conversely, other studies suggest that, for some sectors, like construction, wage growth can recover quickly after storms [26]. As coastal populations and economic assets increase, it will be important to understand how they may be affected by natural hazards and which underlying socioeconomic conditions may differentiate impacts along the coast.

In order to better understand the impacts of natural hazards, as well as the adaptive capacities of human and natural systems, an increasing number of communities are carrying out vulnerability assessments $[27,28]$. However, vulnerability has been and continues to be a contested concept $[29,30]$ as the relationships between the components of vulnerability are often ambiguous and poorly understood [30,31] and there are no agreed-upon methods for the selection and aggregation of indicators [30,32]. In fact, given the practical challenges associated with estimating vulnerability, some researchers have been suggesting that the development of quantitative indicators of vulnerability is neither scientifically sound nor policy relevant, and that these indicators are misleading at best $[30,33]$. The concept of vulnerability, which was introduced in the scientific community in geography and natural hazards research, has been extensively reviewed, as has its application and policy relevance to different geographical locations and circumstances [27,30,34-36]. This is because decision-makers will continue to require such information to inform their decisions, resulting in a continued, and likely growing, demand for vulnerability assessments.

As the concepts of vulnerability are originally derived from several different fields [34,37-40], there is disagreement about the exact definition $[29,41]$. In broad terms, vulnerability has been, and continues to be, approached from at least two different perspectives. Physical scientists have typically taken a natural hazard-based approach, where vulnerability is defined or driven by a physical hazard (so-called outcome vulnerability [42]). While this approach may consider socioeconomic conditions, these are typically framed within the context of a physical hazard. Conversely, social scientists tend to focus more on the underlying characteristics of populations and urban systems that predispose them to harm from a shock or stress (so-called contextual vulnerability [42]). Fortunately, in the general vulnerability assessment literature these conceptual models have evolved and converged over the past two decades to the point where social, economic, cultural, and biophysical factors are recognized as being equally important, e.g., [27,35].

Given that vulnerability is context- and purpose-specific, no framework for operationalizing vulnerability can be considered as better or worse than others $[43,44]$. However, even as the general vulnerability assessment literature has converged, there appears to still be significant divergence within the efforts to map coastal vulnerability, with many studies still focusing on physical hazards and/or biophysical characteristics [45-47]. This may be because one of the earliest mapping efforts-the Coastal Vulnerability Index (CVI)—was entirely based on physical exposure metrics $[48,49]$. It may also be due to the fact that many coastal scientists are not familiar with the broader social vulnerability literature and concepts, or because the focus of coastal assessments tends to be on flooding, which is easy to express and visualize as a physical hazard. Many of these efforts might be more properly framed as exposure or risk mapping rather than vulnerability mapping.

Vulnerability maps are one potential outcome of vulnerability assessments and are often used to visually display the results in an easily understandable manner. In fact, previous studies have 
identified an increasing demand from government agencies and donors to allocate assistance and resources based on spatial assessments (i.e., maps) of climate change impacts [50]. While other efforts reviewed vulnerability mapping more broadly $[35,51,52]$ and, more recently, in the context of the coastal zone [36], the coastal vulnerability mapping products have not yet been evaluated in a consistent and systematic manner. For example, while Bevacqua et al. [36] did an extensive review of over 200 coastal vulnerability studies, they focused more on the conceptual tenants underlying vulnerability and did not examine in detail attempts to quantify and visualize such vulnerability as required by vulnerability mapping. Even though Bevacqua et al. suggest that ecological, physical, and socioeconomic disciplines are increasingly converging in coastal vulnerability studies, there is still a divergence in mapping approaches based on their disciplinary grounding (e.g., physical vs. socioeconomic) and inherent challenges of operationalizing the conceptual elements of vulnerability in a manner that can be visually mapped and displayed. In order to fill this gap, this paper systematically evaluates recent coastal vulnerability mapping assessments (CVMAs) from the peer-reviewed and gray literature to determine the typology of existing studies, applied methodological approaches and mapping products, and their policy relevance. It also identifies new opportunities for innovation to produce more impactful outputs, as well as to provide recommendations for best practices in this field.

Coastal vulnerability mapping has both similarities and differences to the field of climate change vulnerability mapping. For example, both types of mapping inherently struggle with how to visualize the nexus of physical hazards and social vulnerability, often in a world of limited data and complex connections. Both fields also have to address both rapid-onset (e.g., hurricanes, floods) and slow-onset (e.g., sea level rise, droughts) events. Coastal areas are exposed to a broad range of climate hazards, such as extreme winds and rainfall, storm surge from tropical cyclones [53], tidal flooding [54], extreme heat [55], and high humidity in tropical coastal zones [56]. However, coastal flooding is often considered the most frequent and damaging hazard [57]. While flooding can be driven by different processes (e.g., sea level rise, storm surge, and riverine), a focus on flooding can allow for a more rigorous definition of vulnerability, especially as compared to the broader concept of "climate change" vulnerability. This allows hazard exposure to be more easily geographically defined, which provides a more distinct spatial context for determination of the vulnerability of place. It also permits a more specific selection of socioeconomic variables and demographic characteristics that define vulnerability [58], since the factors that determine sensitivity and adaptive capacity are narrower than they would be if the focus were on a wide spectrum of climate change impacts (e.g., changes in rainfall, increase in temperature).

However, a focus on flooding can also have its challenges. For example, other vulnerability assessments often use administrative units as the unit of analysis (e.g., changes in rainfall will affect an entire administrative unit in a somewhat similar manner) because they are often seen as the most policy-relevant unit of analysis. However, the spatial extent of flooding, especially coastal flooding, rarely conforms to administrative boundaries. Thus, it is possible, and often likely, that only a small portion of an administrative unit will experience flooding (e.g., shoreline fringes and corridors along the waterways). Therefore, administrative units often are not representative of an appropriate scale for coastal vulnerability analysis, and displaying coastal vulnerability maps delineated by administrative units can skew the perception of flooding extent and impact. Perhaps more importantly, a narrow hazard focus can shift the attention to the physical dimensions of the problem at the expense of the socioeconomic and cultural aspects. This tendency can be exacerbated by the difficulty of obtaining sociodemographic data at flood-relevant spatial scales such as parcel or block group levels, especially in the developing world [58].

\section{Materials and Methods}

The approach used in this paper was informed by an earlier systematic review of climate change vulnerability mapping case studies [52] in which the co-authors were involved, and represents a complementary effort focused specifically on coastal vulnerability mapping, with adjustments to the methodology to support assessment in the coastal context. Similar to the original study, our strategy 
included the development of core sample selection criteria to identify papers suitable for the assessment, the protocol for systematic assessment of selected articles, and the coding procedure and analysis. The primary selection criteria for inclusion of papers in the core analysis sample included the following:

- Papers should address at least one of the following climate- and non-climate-related coastal hazards: tsunamis, hurricanes/cyclones/typhoons, storm surge, coastal flooding, sea level rise, waves, and high winds in a coastal setting (including both single- and multi-hazard studies).

- Analysis should assess the vulnerability and/or risk to people/population/infrastructure of at least one of the aforementioned hazards. Studies focusing only on an ecosystem or physical vulnerability without any reference to a socioeconomic element were excluded from the consideration.

- Papers must contain at least one map of vulnerability and/or risk showing integrated socioeconomic and climatic/biophysical dimensions or an indirect coastal hazard dimension that influenced the selection of socioeconomic variables but was not directly integrated or quantified in the map. Studies containing maps of other elements (e.g., elevation or land cover), but not maps of vulnerability and/or risk, were not considered for inclusion in the core sample. Maps are considered the focal products of vulnerability assessments as they visually communicate risk distribution over different spatial scales to decision-makers and other stakeholders [52].

After applying the primary criteria, we applied a second tier of criteria ensuring that the selected studies (i) were written in English because it is the dominant language of global scientific discourse; (ii) include either peer-reviewed journal articles or gray literature from reliable sources such as government agencies and international organizations (e.g., reports, working/white papers, and technical documents); (iii) exclude MS theses and PhD dissertations due to their length and formatting that would skew the analysis; and (iv) were published in or after 2004 (a web search did not yield any relevant results using ours criteria before this year). In order to capture both gray literature and scholarly articles, we conducted a search in June 2017 on Google Scholar to identify the potential candidates using the following key words and their combination ( $n=$ search results): "vulnerability mapping" and "storm surges" $(n=523)$; "vulnerability mapping" and "sea level rise" $(n=1090)$; "vulnerability mapping" and "coastal flooding" ( $n=316)$; "vulnerability mapping" and "hurricanes" $(n=538)$; "vulnerability mapping" and "cyclones" ( $n=709)$; "vulnerability mapping" and "tsunamis" $(n=407) ;$ "vulnerability mapping" and "typhoons" ( $n=246)$; and "vulnerability mapping" and "high winds" $(n=96)$. For each combination of keywords, we sorted out the entries by relevance and reviewed only the first 500 listed results (for all combinations of keywords, no relevant papers were identified after the 300th result).

In addition to the Google Scholar search, we included several papers focused on the coastal context from the studies gathered for the original meta-analysis vulnerability mapping effort [52]. This approach yielded a total of 89 papers, of which 24 were later discarded after closer evaluation as they did not fully meet the selection criteria (e.g., they contained maps but not a map of vulnerability, were duplicates of other similar studies, or were large reports with very little focus on coastal vulnerability). That left a final core sample of 65 papers/reports (available in appendix B of the Supplementary Materials) that were used in further analysis. In addition to collecting general study identifiers (e.g., title, year, and publisher), our protocol for the systematic content analysis included information on scale, location, and thematic focus; what is being measured; vulnerability assessment approach and data source; mapping product; and policy relevance. The specific coding criteria can be found in appendix $C$ of the Supplementary Materials. Three coders synchronized the coding strategy, evaluated assigned articles, and noted their responses as an assigned code letter, qualitative observation, or full text excerpt for the NVivo analysis of content.

The policy-relevant text was extracted from the individual papers and transferred to the NVivo (QSR International, LLC, Burlington, MA, USA) software platform for qualitative data analysis to measure the word frequency of excerpts ( 30 most frequent words with a minimum length of four letters and exact matches). (The research monograph by Baum et al. (2009) was excluded from the NVivo analysis due to its length and the presentation of information in tabular format, which would affect the content counts 
and skew the results.) We used stemmed match word frequency to capture all possible expressions based on a single stem, considering that using stemmed versus exact match word frequency generally leads to similar outcomes [59]. Results were also displayed as a word tree to visualize the keywords in relation to the adjacent text. This visualization technique helps identify the repetition of contextual words and phrases associated with the searched keywords to better understand their meaning in the text [60]. A word tree output shows a root keyword in the center, the prefix words on the left side of the root keyword and suffix text branches that occur after the keyword on the right side.

\section{Results and Discussion}

\subsection{Characteristics of Reviewed Studies}

\subsubsection{Publication Types, Dates, and Discipline Studies}

The final sample of coastal vulnerability mapping assessment (CVMA) studies consisted mostly of journal articles $(n=55)$, followed by reports and working papers $(n=8)$ and conference proceedings $(n$ $=2$ ). Among the journal articles, the top publication outlets include Natural Hazards $(n=8)$ and Ocean and Coastal Management $(n=4)$, followed by a range of journals from various research domains, such as the Journal of the Indian Society of Remote Sensing, Applied Geography, and Climatic Change. This wide range of disciplinary backgrounds likely contributed to the breadth of frameworks and methodologies used to produce the final mapping products.

The number of published CVMA studies increased gradually from 2009, with an upsurge in publishing in 2014-2016 (Figure 1). This continual increase may indicate either scholarly response to a higher demand for this type of information or the growing interest of the research community in using vulnerability assessments to study hazard-related complexities in coastal systems. It may also suggest that this trend reflects more confidence among researchers in exploring the nexus of physical and social circumstances in the coastal zone, using vulnerability mapping in parallel with the advancement and visibility of the vulnerability field in other disciplines. Lastly, it may be possible that, once a new methodology is published, it will lead to its reproduction in other contexts and different geographic areas. As a part of the evaluation, we also assessed the papers' disciplinary grounding and found that about half of the papers (i.e., $n=32$ ) fell under the natural hazards and disaster field, about one-third ( $n$ $=19)$ were focused on climate change, and the rest $(n=14)$ discussed both aspects but did not always include both of them in the estimation of vulnerability. This demonstrates the continued interplay between a variety of disciplinary backgrounds in the conceptualization of coastal vulnerability.

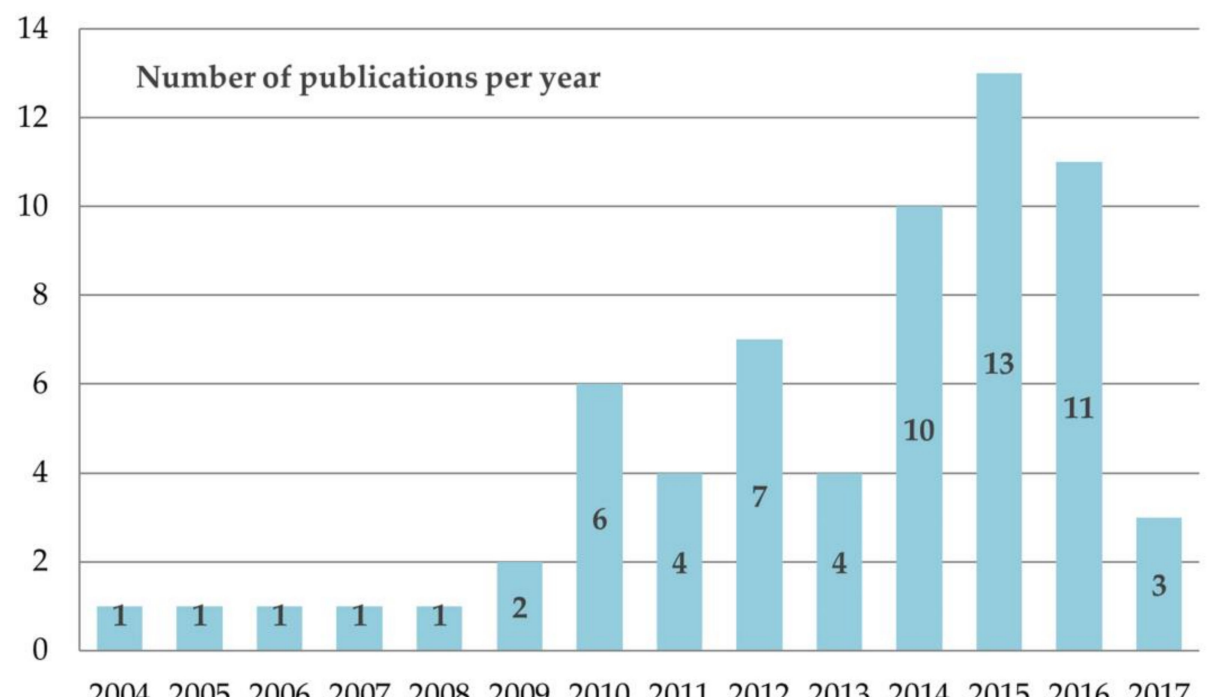

Figure 1. Publishing trend of Coastal Vulnerability Mapping Assessments (CVMAs). 


\subsubsection{Interdisciplinarity}

Coastal vulnerability studies are conducted by scientists from a wide range of disciplinary backgrounds. As such, they do not follow a single methodological framework or position themselves within a singular discipline. Instead, the assessments often position themselves in between the fields of natural hazards, disasters, and climate change, or have an ambiguous disciplinary designation (e.g., coastal or flooding). However, there are subsets of papers that seem to follow somewhat similar approaches. For example, Kunte et al. [61] suggest that most studies using the Coastal Vulnerability Index to evaluate coastal vulnerability in India focus primarily on geomorphological factors affecting exposure. In our case, numerous studies are geographically focused on vulnerability in India $(n=15)$ and in many cases build upon each other conceptually and methodologically.

Furthermore, many papers provide a high level of technical detail on data preparation, transformation, integration, and visualization that culminate with composite output maps, but such papers often lack a discussion of the broader implications of results and their policy relevance. This may suggest a more physical disciplinary or technical focus on a hazard, as opposed to a holistic approach that seeks to address vulnerability more broadly (e.g., by integrating human, ecological, land use, and other dimensions). The exception to this is papers with interdisciplinary authorship, which tend to account for a more diverse set of physical and social variables and offer more explicit policy recommendations. For example, some studies introduced innovative aspects to a standard methodology by including novel variables, methodological improvements, and validation or sensitivity analysis. A few papers included primary data collection via focus groups, interviews, questionnaires, and surveys to identify variables for index construction, validate their selection, or weight them for analysis [62-65].

Four studies used the expert knowledge/opinion for ranking and weighting [66-69]. In a more recent example, Trzaska et al. [70] took a bottom up approach to the development of coastal climate change vulnerability assessment by integrating the input on household profile, knowledge and attitudes toward mangrove conservation, perceptions on climate change, and community resilience, coping capacity, and adaptation obtained from household surveys and the Participatory Rural Appraisals (PRAs) discussions. Overall, there still appears to be a disciplinary bias within coastal vulnerability mapping studies, where either the physical or social aspects are emphasized. This remained true even in our sample, where we specifically tried to select only those papers that looked more holistically at vulnerability. This may indicate that further efforts are needed to reinforce the importance of both the physical and social aspects of vulnerability.

\subsubsection{Geographical Coverage and Scale}

The vulnerability assessments in our sample were mostly conducted at the local $(n=37)$ and regional/subnational $(n=21)$ scale. Even though the study selection was biased by the English-only criteria, these studies covered coastlines on all continents (except Antarctica), with Asia $(n=30)$ and North America $(n=17)$ being most represented in the sample (Figure 2). Accordingly, the most covered countries are India $(n=15)$ and the United States $(n=14)$. The African continent, despite its high percent of population living on the coast, was underrepresented, with only four studies. This geographic distribution likely reflects the level of awareness of and/or experience with coastal hazards, endorsement of CVA methodology in both scientific and policy arenas, and data availability. It may also be driven by the need to anticipate risks to protect valuable assets that tend to be concentrated in coastal areas of more developed countries. Two papers looked at the vulnerability of islands, which were counted in the local category. 


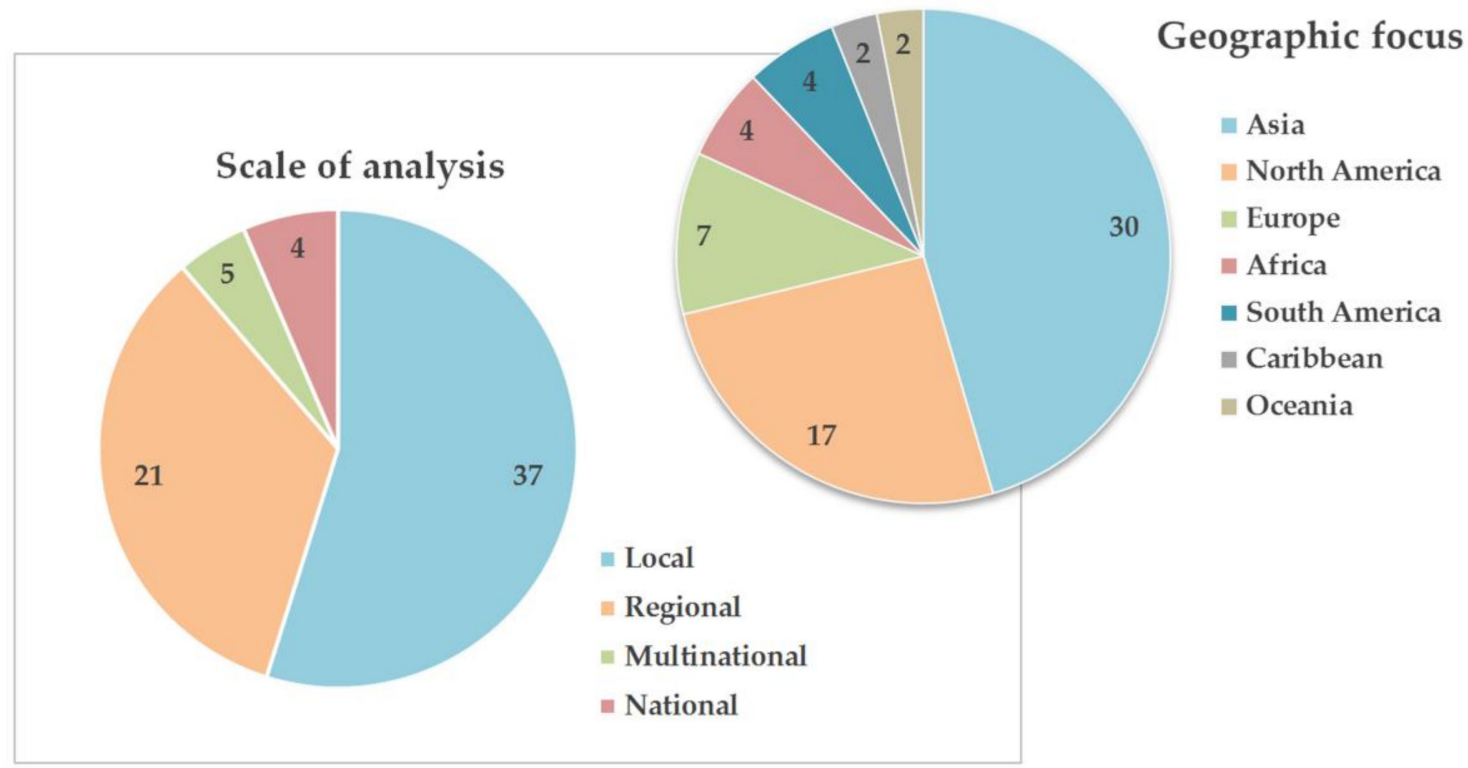

Figure 2. Scale of analysis and geographic focus of CVMA papers in the literature sample.

It is not surprising that most studies looked at a subnational scale, given that coastal flooding represents a place-based hazard, making it more difficult to accurately assess and visualize at large spatial scales. Having a sample set that covers a broad range of geographies is important; however, as noted above in the case of India, a geographically confined set of assessments may be biased toward a single methodological approach. A geographic bias, especially one focused on the United States, could also affect the results of this analysis owing to data availability considerations. However, it should be acknowledged that the English-language-only criterion likely reduced the number of assessments for Latin America and perhaps French-speaking Africa, which may have introduced bias in our results.

\subsection{Vulnerability Assessment Methods}

\subsubsection{Characterization of Coastal Hazards}

Some papers were focused on a single specific coastal hazard $(n=24)$, while others considered multiple hazards and attempted to describe cumulative exposure $(n=41)$. In our sample, vulnerability to coastal flooding was assessed in 38 studies, to storm surge in 31 papers, to sea level rise in 30 studies, to other categories such as shoreline change or unspecific coastal hazards in 23 papers, to hurricanes/cyclones/tropical storms in 13 studies, and to tsunamis in 7 papers. However, it should be noted that coastal flooding is not a conceptually distinct hazard from storm surge and sea level rise, which also result in flooding. Similarly, storm surge is not distinct from hurricanes. It is possible that the differences in hazard characterization are owing to disciplinary differences or to attempts to capture policy interest.

Although coastal areas are experiencing a range of climate challenges, the most pressing and pervasive hazard is clearly flooding, regardless of its cause. Likewise, the majority of CVMA studies indicated flooding as a key threat to the coastal zone, while others were focused on hazards that still result in flooding. Even though there is a difference between episodic events with rapid onset (e.g., hurricanes and nor'easters), and chronic occurrences with slow onset (e.g., sea level rise and tidal flooding), the end result is still flooded land. The majority of the studies reviewed use a simplistic representation of flooding, such as LiDAR or SRTM-based Digital Elevation Models (DEMs), to delineate surface areas at risk of flooding rather than more complex hydrodynamic models of water propagation within the study area, e.g., [71-73].

Considering it is easier to spatially delineate and quantify exposure to coastal flooding than to other climate hazards like extreme heat and precipitation, some CVMA methodologies tend to 
oversimplify the problem by using, for example, arbitrary inundation levels, e.g., [74,75] or regional values provided in IPCC scenarios, e.g., [76]. Some authors deemed it sufficient to use a bathtub approach solely based on DEMs to depict the exposure, e.g., [77-79]. Such bathtub models, based on the difference between the projected flood water height and elevation, have limited utility as they do not account for the hydrological connectivity and geophysical barriers present in the real settings [80]. Strauss et al. [81] noted that this approach may fail to incorporate the reduced drainage and water movement via smaller channels and porous rock, but also acknowledged that the main goal of many assessments is to indicate areas of potential concern, and provide a broader baseline for additional analysis rather than to generate precise flood risk maps.

Flood extent and propagation is also influenced by many nonclimatic factors and indirect landward and seaward influences such as urban development, proximity of built environment to coastline, sediment shortages to restore the land loss, quality of coral reef, and type and extent of human activities in coastal zone [82]. Furthermore, the co-occurrence of storm surge and tidal flooding with heavy precipitation from either pluvial (surface runoff) or fluvial (riverine flooding) sources has been increasing and can compound the problem of coastal flooding [83]. Geoghegan et al. [84] suggests that models of tropical cyclone flooding should account for the increased rainfall intensity and related freshwater flooding to improve their accuracy and impact.

Coastal flooding models can also be improved by the inclusion of specific boundary conditions, terrain cover and hydraulic infrastructure, spatiotemporally variable overtopping flows features, location-specific rates of land subsidence, different hydrological inputs, routing overland flows, and shoaling groundwater [85]. Significant advances have been achieved in dynamic flood modeling that consider other relevant attributes such as tidal oscillations, seasonal climate variability, storms, erosion, and shoreline change [86]. Tebaldi et al. [87] found substantial changes in the frequency of extreme water levels in locations with relatively low and gradual SLR, further advocating for policy approaches that will account for the nonstationary behavior of extreme events when evaluating future climate risks.

Moreover, coastal river deltas and their complex and highly interrelated ecological, social, and economic components, such as upstream water diversion, sediment depletions by upstream structural interventions, algae blooms, and other processes make coastal river deltas hotspots of vulnerability but also systems that require dynamic study approaches [88]. Studies on vulnerability in deltaic areas either focus on local case studies or single hazards instead of applying a social-ecological systems perspective that is less well understood, often resulting in the identification of risk reduction and adaptation strategies that are based on incomplete assumptions [89]. In the context of vulnerability assessments involving tropical cyclones, Hoque et al. [90] concluded that very few studies on cyclone risk mapping and modeling incorporated climate change scenarios and SLR projections in their assessment, and those that did applied global SLR scenarios at the regional scale.

In our assessment, the CVMA studies used many different approaches to estimate flood hazards based on the selected analytical scale, the main objectives of the study, and the attributes associated with the geographic location of interest. Consequently, it is more reasonable to expect the application of complex hydrodynamic models in locations where granular geospatial data are available and billions of dollars in assets are exposed, while in others, such as Africa, with limited data availability to support such models and relatively lower economic risk, a simplistic approach to risk delineation may be the only one possible or reasonable given the lower cost-benefit ratio. The uncertainty in predictions and gaps in spatiotemporal scale (e.g., direct exposure to flood versus indirect challenges such as limited accessibility or estimates on spatial level that are not aligned with the actual flooding exposure) may leave enough ambiguity for decision-makers to discourage them from using coastal vulnerability assessments in policy-making.

This may be especially true for some papers that are focused on the broader policy implications of flooding or on alerting decision-makers to emerging problems in their localities. The acute/episodic and chronic/progressive nature of coastal hazards can help characterize sensitivity and adaptive capacity of place, which are centered on property damage and evacuation for rapid onset events and on permanent 
relocation and loss of assets for gradual persistent changes. At the same time, this may present some difficulties with vulnerability analysis in that coastal hazards may be localized (e.g., along the shoreline or waterways) but have a propensity to propagate further inland depending on the circumstances (e.g., the magnitude and severity of the event itself and co-occurrence with other hazards that may amplify its impacts).

\subsubsection{Vulnerability Frameworks}

Considering that our core sample included studies originating from natural hazards and disasters $(n=32)$ and climate change disciplines $(n=19)$, or both $(n=14)$, the authors used various vulnerability frameworks in their CVA analysis. Only a few studies employed the IPCC vulnerability (AR4) framework [62,91] (appendix A of the Supplementary Materials). A few studies employed the Social Vulnerability Index (SoVI) introduced by Cutter et al. [92] (e.g., [93,94]), while others developed their own vulnerability framing, like the Vulnerability Extreme Index [76], Vulnerability Index for Human Life [95], and Computed Coastal area Flood Vulnerability Index (CCFVI) [96]. Many studies used the Coastal Vulnerability Index (CVI) introduced by Gornitz [48] and Thieler and Hammer-Klose [97], which focuses on seven key biophysical measures (geomorphology, slope, shoreline change rate, sea level rise, tide range, bathymetry, and wave height), indicating continued usage of approaches that focus almost solely on the exposure aspects of vulnerability. Such studies made occasional modifications to data transformation techniques and/or to account for the additional socioeconomic aspects, e.g., [98] combined a CVI with SoVI to create a Place Vulnerability Index (PVI)). A diversity of applied vulnerability frameworks leads to substantial differences across the sample studies in terms of the variables included and the aggregation process. Some vulnerability frameworks in our sample were created anew, with newly proposed components and considerations, while others followed established structure but applied some modifications. While the IPCC AR4 framework calls for the holistic integration of the wide range of vulnerability aspects, other frameworks, in particular CVI and SoVI, tend to focus on either the biophysical or social dimensions of vulnerability.

Some studies solely focused on social vulnerability and did not account for any hazards. Here it is assumed that the underlying social vulnerability will predispose certain populations to be more vulnerable to all hazards. Conversely, a few papers included only biophysical considerations, with little or no mention of socioeconomic aspects. It appears that papers solely focused on biophysical vulnerability were often authored by coastal oceanographers who may not be familiar with (or as interested in) issues around social vulnerability. Furthermore, in those studies that focused on the limited spatial extent of the coastal periphery (i.e., the zone directly adjacent to the ocean), such as those looking at coastal erosion, it may be more challenging to meaningfully integrate biophysical variables with relevant socioeconomic information from areas further inland where people actually live. Conversely, papers focused on general flooding may be better able to justify the relevance of social aspects, as inundation would affect a larger populated area. Applying the CVI and SoVI, e.g., [99], to the same context is one of the possible ways to characterize both biophysical and socioeconomic attributes, even though they are still differentiated and combining them into a single measure of vulnerability is not straightforward.

In some studies, it was difficult to determine what exactly had been done and how the vulnerability mapping outputs were generated. This ambiguity in methodology is sometimes observed in inadequate description of data sources or in data transformation procedures and aggregation. Often, the vulnerability metrics were derived from proxy measures or reflected general knowledge (e.g., assuming that coastal areas are more vulnerable because they are on the coast or that urban areas are more populated and therefore have higher exposure). For example, Islam et al. [100] incorporated population density in the Coastal Vulnerability Index (CVI) as reflective of socioeconomic impacts, under the assumption that higher exposure signifies higher vulnerability. It appears that authors often did not fully account for socioeconomic information due to challenges with turning them into quantified values that could be mapped or integrated into an overall vulnerability ranking. Furthermore, variables in 
the reviewed vulnerability assessments come from many different primary and secondary sources, or a combination of them, or include new attributes reflecting transformed and processed data using various statistical and GIS procedures.

It appears that the variables selected are often more reflective of the available data than the connection of that data to the concept of vulnerability. In the majority of cases, variables were equally weighted and not always justified based on their relevance to coastal vulnerability. With the exception of CVI, which has a more consistent framework, we observed a lack of cohesion in assessment approaches and transparency on which data were considered and why, as well as what the possible implications of the data transformation and aggregation approach are for on the final result. We observed a similar pattern in the meta-analysis of climate vulnerability assessments [52], where many studies reproduced existing methods with some modifications and rarely included a critical evaluation of the selected statistical approach or assessment of uncertainty (e.g., through a sensitivity analysis). In a more recent effort, Woodruff et al. [81] engaged in this dialogue by evaluating the role of GIS in coastal vulnerability to climate change and identified the challenges of this approach such as data availability and data error, the inclusion of uncertainty, and relevance to decision-making processes and policy implementation. Still, as noted in the introduction, there is no agreed-upon framework for data selection and aggregation across multiple dimensions that shape coastal zones.

\subsubsection{Impacted Systems}

Reflecting the use of diverse vulnerability frameworks, the sample studies considered many different impacted systems in their vulnerability assessment. While a focus on the vulnerability of people and infrastructure was a key criterion used to select the studies, not all of them explicitly considered human dimensions. Our analysis found that 14 studies only indirectly considered the human system in their vulnerability assessment (e.g., by focusing on populated coastal areas, urban municipalities, or economic activity), while eight only included population density (Table 1). The majority of studies using CVI incorporated only geological and physical variables, with a focus on infrastructure, without any references to human dimensions. This is particularly the case for studies focusing on the Indian coast $[47,101,102]$. Conversely, studies that employed an adapted SoVI framework often included only human-related variables [103] and did not account for physical dimensions. Among all of the studies that explicitly integrated the human dimension, the most common measure of human systems was population $(n=28)$, followed by socioeconomic $(n=22)$ and sociodemographic considerations $(n=15)$.

Table 1. Impacted systems and their frequency of occurrence within the sample papers.

\begin{tabular}{|c|c|c|c|c|c|c|c|}
\hline Human System & $n$ & Economic System & $n$ & Built Environment & $n$ & Natural System & $n$ \\
\hline Population & 28 & None & 53 & Infrastructure & 24 & $\begin{array}{l}\text { Topography and } \\
\text { geomorphology }\end{array}$ & 28 \\
\hline Socioeconomic & 22 & Other & 7 & None & 20 & None & 26 \\
\hline Sociodemographic & 15 & Fisheries & 4 & Housing & 14 & Coastlines (type) & 23 \\
\hline Indirectly implied & 14 & Agriculture & 4 & Urban land use & 14 & Cover & 20 \\
\hline Economic & 11 & Industry & 4 & Other & 13 & Erosion & 15 \\
\hline Other & 10 & Pastoralism & 0 & Indirectly implied & 10 & Other & 10 \\
\hline Health/medical & 9 & & & Critical facilities & 10 & $\begin{array}{l}\text { Wetlands, seagrasses } \\
\text { mangroves, dunes }\end{array}$ & 9 \\
\hline Governance/institutions & 4 & & & & & & \\
\hline
\end{tabular}

Those studies that included socioeconomic considerations incorporated a variety of human-related variables, such as the type of cooking fuel used, access to safe drinking water, banking services, or radios, e.g., [95], or conflict and tourist density data. These variables are often included as proxies for the socioeconomic factors that make people more or less vulnerable to stressors. Only four studies included variables related to governance and institutions $[64,67,96,104]$, even though these aspects play a vital role in coastal decision-making that shapes their vulnerability. This is not surprising as 
spatially delineated proxies for such conceptual variables are difficult to quantify and generally lack spatially explicit delineations.

The economic system was rarely considered and mostly in specific contexts (e.g., forestry; saltpans; cocoa, coconut, palm oil, and banana production; real estate; and tourism), with more than $80 \%$ of our sample studies overlooking this important aspect of coastal resilience. Systems more often included the built environment, which is addressed in $70 \%$ of our sample studies, mainly by inclusion of variables related to the infrastructure or to housing and urban land use. Other variables related to the built environment include cultural assets, shelters, cultural and historical landmarks, commercial areas, and dams/levees. The inclusion of the built environment is not surprising, as such an environment is easy to conceptualize and visualize as related to flooding hazards (e.g., the flooding of a building). However, loss or damage to critical facilities was only considered in 10 papers, mostly as an implied measure. The natural system was included in $60 \%$ of papers, mainly via variables related to topography, geomorphology, and types of coastlines. Some other variables linked to the natural system included the land cover-often with a specific interest in wetlands, mangroves, or dunes-and erosion of the shoreline. However, the natural system was often considered in terms of contributing to or mitigating vulnerability, as opposed to a vulnerable system itself (e.g., mangroves were considered to reduce floods).

This wide range of impacted systems and included variables likely reflects the fact that researchers are approaching the concept of coastal vulnerability from different disciplinary backgrounds and often with limited data. However, considering there is no prescribed list of indicators to measure vulnerability, researchers have to make the final decision on which ones will be included based on the specific objectives of the assessments and data availability [81]. For example, many of the variables noted above were used as proxies for more complicated conceptual aspects of vulnerability, while things like population density were used in the absence of more appropriate socioeconomic data. Data availability is an important consideration as there are vast disparities in such availability between developed and developing countries. The somewhat arbitrary selection of data used and systems analyzed is further discussed in Section 3.2.5.

\subsubsection{Index Construction}

We found that the majority of our sample studies (52\%) constructed a vulnerability index using aggregation of several components, while the remaining papers created an index without grouping variables into components such as exposure, sensitivity, and adaptive capacity (25\%), or did not compute a combined index (23\%). Some papers were highly focused on technical aspects of index construction and provided extensive description of individual variables, data transformation and aggregation procedures, and visualization. However, such papers often had a limited discussion on policy relevance and the implications of the findings. Other papers provided a limited level of detail about methodological procedures or inadequate information on data sources, both of which may reduce research reproducibility. It is difficult to tell if a focus on the methodology over policy relevance is reflective of the often limited space available in peer-reviewed journals, or of a difference in importance assigned to each by researchers from different disciplinary backgrounds. When space is a limitation, authors can consider including detailed information on the data as well as the transformation and aggregation procedures in the Supplementary Materials in order to allow for a fuller discussion of the relevance of the findings.

\subsubsection{Uncertainty Assessment and Other}

Most of the sample studies $(n=38)$ did not account for or comment on uncertainty in the assessment. Twenty papers included only a textual discussion of uncertainty, three studies provided both a textual discussion and quantitative assessment of uncertainty, and five studies included a mapping (or visualization) of uncertainty, e.g., [66,105]. A few studies included the uncertainty discussion in a section on study limitations. Among studies that included a qualitative discussion on 
uncertainty, some papers provided a comprehensive discussion of different sources of uncertainties (e.g., secondary data, modeling, vulnerability framework, and proxy measures [106] and others), while others provided only brief and vague statements, such as "the results are strongly related to the number of variables used and the inherent element of subjectivity in the development of each index" [80] (p. 830). Given the lack of an agreed-upon methodology or set of necessary input variables, an uncertainty assessment is important for determining the credibility of an assessment. It is clear that different exposure metrics, socioeconomic proxy measures, aggregation methods, and weighting schemes can influence the outcomes and thus the vulnerability ranking. Yet, a discussion and quantification of uncertainty is often not included in coastal vulnerability mapping assessments, possibly because it is arduous and time-consuming, may introduce confusion among end users, especially decision-makers, who prefer definite recommendations, and may indicate ambiguity in an approach, thus giving the impression that the study is methodologically weak. Another reason that uncertainty may not be explicitly addressed is because there is no agreed-upon framework or methodology for assessing uncertainty with regards to vulnerability, which is itself a poorly defined and perhaps unquantifiable concept [30].

Only four studies included a validation step $[67,68,76,107]$. Validation tells us whether the assessment is measuring what it is supposed to measure and can be accomplished using an alternative dataset at a different spatial resolution or statistical techniques [108]. Molinari et al. [109] note that very few studies include validation of flood risk estimates and maps, which may be concerning considering that decision-makers rely on these products to make hazard mitigation investments and plans. In a more recent example, Krishnan et al. [110] conducted a validation of individual indicators using multiple statistical procedures to ensure they are not overrepresented in the final Cumulative Vulnerability Index (CVI) for the Sindhudurg district in India.

Furthermore, an assessment of hazard data and their sources reveals that the majority of papers $(n=39)$ employed hazard information from a single point in time, followed by those that used recent multiyear estimates $(n=14)$, future projections $(n=10)$, or did not measure any physical hazards $(n=6)$. In the latter cases, it was implied from the introduction that coastal locations are prone to hazards and therefore represent high-risk places. A majority of papers relied solely on secondary data $(n=37)$, while fewer studies used primary data $(n=25)$. The rest $(n=17)$ did not model hazards or specify the data sources, or used arbitrary estimates. This signifies that there is a wide range of data and information being used to estimate the exposure hazard, which is methodologically sound as long as the information and time frame being considered within a study are relevant to the intended purpose. For example, studies that look at future hazards often include projected hazard data, but current socioeconomic data. The limitations of using static hazard and socioeconomic data should be explicitly acknowledged within the assessment.

\subsection{Coastal Mapping}

\subsubsection{Mapped Components}

One of three key criteria for inclusion in this analysis was the presence of at least one map of vulnerability (and/or risk), either integrated or presented as an overlay. Beyond this criterion, we also explored whether the studies displayed maps of individual vulnerability indicators such as physical hazards, socioeconomic considerations, environmental variables, and aggregated components such as exposure, adaptive capacity, or sensitivity (Figure 3a). Results show that very few studies $(n=6)$ provided only a map of integrated vulnerability, e.g., [62,72], while the majority of papers also displayed the physical hazard $(n=38)$, socioeconomic aspects $(n=31)$, and/or environmental variables $(n=21)$. Only a few studies provided maps of aggregated components of vulnerability (e.g., Mahapatra et al. [80]) (Figure 3b), even though such intermediate maps may be very helpful to better understand the overall vulnerability. This seems odd given that over half of the papers indicated such subcomponents were estimated and then aggregated into a measure of vulnerability. It is possible 
that a lack of such figures is owing to the space limitations imposed by many journals or the various subcomponents having a similar spatial distribution to the final vulnerability metric.

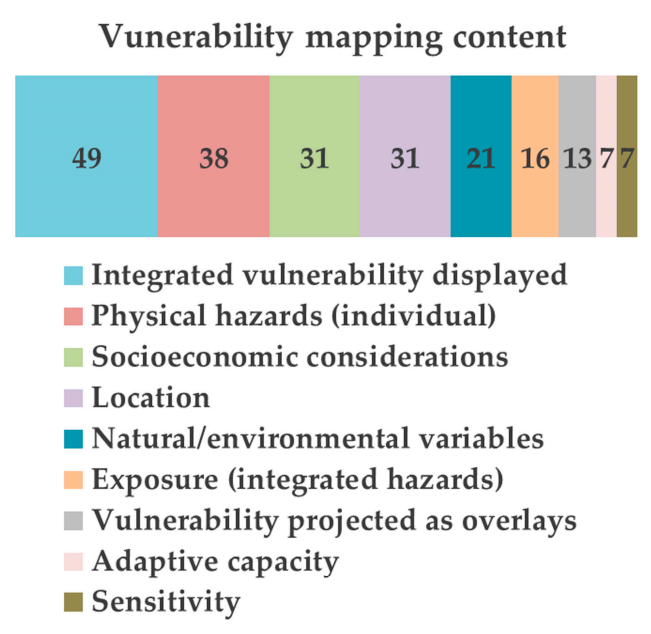

(a)

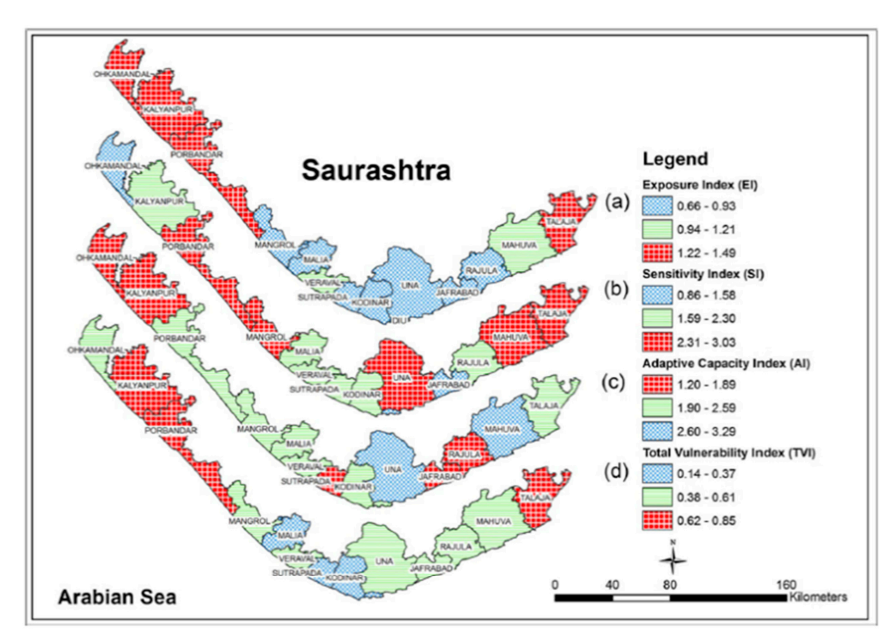

(b)

Figure 3. (a) Vulnerability mapping content; (b) example of map with individual and consolidated components [80].

\subsubsection{Cartographic Representation of the Coast}

In our study sample, papers defined the coast in different ways, from referring to coastal administrative jurisdictions to delineation along the coastline. This is not surprising as there is no agreed-upon definition of what "coastal" entails. Unfortunately, such a definition is unlikely to be produced in the near future as it would involve discussions across a range of disciplinary and institutional perspectives. For example, the National Oceanic and Atmospheric Administration (NOAA) recognizes that many researchers use administrative boundaries like counties in analysis and, therefore, offers a distinction between watershed and coastal counties, with the former representing counties located in the watershed area and the latter being directly adjacent to the open ocean, major estuaries, and the Great Lakes [111].

In our case, some studies included only the beach or arbitrary corridors along the shoreline as the unit of analysis (typically those focused on coastal erosion), while others included the whole administrative units under the assumption that these units are exposed to coastal hazards by proximity. However, depending on the size, shape, population distribution, and other aspects of the physical environment, the risk may differ significantly within an administrative unit. The choice for this analytical level may reflect the lack of granular data that would allow for the assessment of socioeconomic characteristics on smaller levels like parcel or census block level or detailed biophysical data that provide spatially explicit geomorphological information (i.e., height above sea level). Another reason for the selection of administrative units may be that the findings are made more relevant for local decision-making. In our sample, the majority of the spatial units used in mapping were administrative boundaries $(n=26)$, grid cells $(n=23)$, coastal risk delineation $(n=16)$, and parcel level/property $(n=$ 2), while none included natural/topographic boundaries.

Similar to many of the choices made in the assessments examined here, the unit of analysis is a subjective one that does not have a single right answer. The choice will be dictated by the data available, the question or challenge being addressed through the assessment, and/or the intended audience for the study. In the end, the important point is that the unit of analysis is considered carefully and tailored to the specific context of the study. For example, if one is concerned with the impacts of coastal erosion, then the administrative unit is unlikely to be the correct unit of analysis. Conversely, if 
one only has socioeconomic and demographic data available at the administrative unit level, trying to create more spatially resolved estimates of vulnerability may not be appropriate.

\subsubsection{Vulnerability Map Features}

The maps in the studies assessed were evaluated for the presence of specific features that reflect cartographic conventions. We found that basic cartographic elements are missing from a number of maps, such as scale bar in $19 \%$ and features that help identify location in $35 \%$ of maps (e.g., Figure 4a, [73]). The absence of these features may reduce map comprehension and thus policy relevance. Further, $22 \%$ of maps employed numerical legends presenting the raw vulnerability boundaries of each class (e.g., Figure 4b, [112]). While technically accurate, such numerical legends are often more difficult for lay audiences to quickly interpret, and thus can reduce map comprehension and utility.

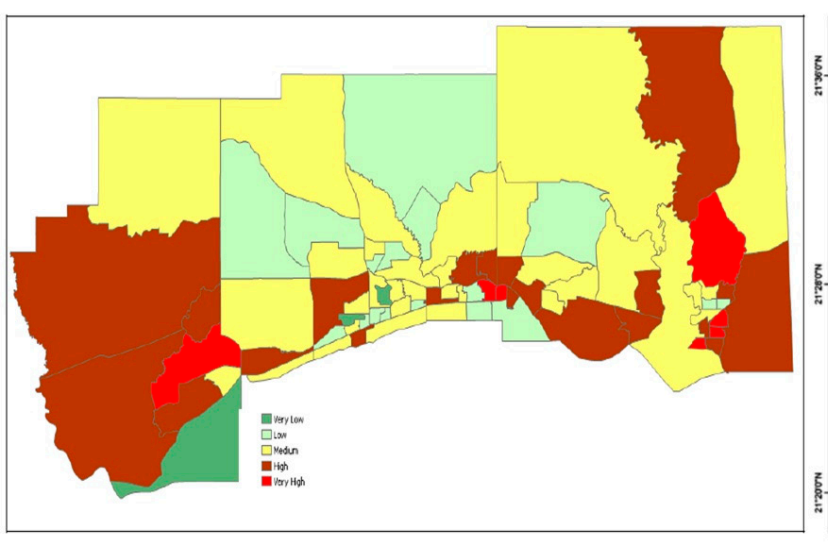

(a)

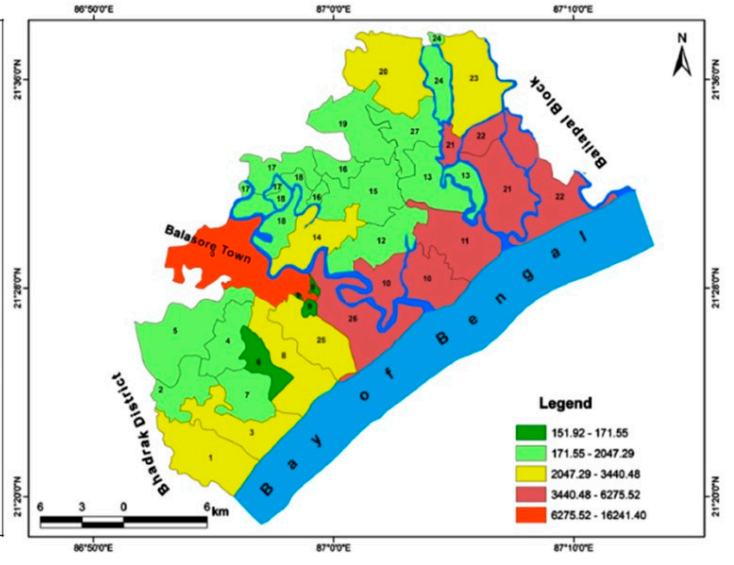

(b)

Figure 4. (a) Map without location identifiers and scale bar [73]; (b) map with unnormalized numerical legend [112].

All the maps were presented in 2D and most of them $(n=59)$ included a legend. In addition, 39 maps had delineated boundaries between units of analysis, but only 31 included a map title, and 12 had poorly defined vulnerability classes. Lastly, 57 maps were in color and eight were black and white. This last finding could be of importance, as while color maps are often easier to interpret, they can lose their effectiveness if they have to be reproduced in a noncolor format. Similar to the other subjective choices being made during the assessment, the presentation of the findings should carefully consider the intended audience and likely means of presentation.

In terms of more qualitative observations, 32 maps lacked labels that would help determine the geospatial orientation, and a significant number of maps had a simple design. In some cases, this simple design can facilitate engagement with the presented information and comprehension among broader audiences, while highly detailed and complex mapping products with multiple facts may be more difficult to understand. Twenty-three maps had poor resolution, 19 small/hard-to-read font, and for 18 maps it was difficult to distinguish between colors/patterns. In addition, 23 maps had incomplete labels and map description and 12 lacked a clear legend. These findings are consistent with results from the larger systematic review of climate vulnerability mapping efforts [52], which also found that many assessments failed to follow cartographic best practices.

Of the 65 vulnerability maps that we reviewed, only four had all the elements deemed necessary for a sound vulnerability mapping product [75,113-115] (e.g., legend clarity and interpretability, high resolution, appropriate and easy-to-read title and labels, and features indicating geospatial position and key landmarks). The other maps had some limitations that could affect their accurate interpretation, such as different orientations and projections of maps throughout the paper, lack of labels indicating 
which side of the map is facing water versus land, and a description of map codes integrated into the text rather than in the figure caption. Considering that a majority of coastal vulnerability mapping studies culminate in vulnerability maps as their final and most important product, particular attention should be paid to proper map design. This is particularly true if the authors expect those maps to be used to inform decision-making. Guidelines to enhance the quality and comprehension of vulnerability mapping products to support decision-making are discussed in de Sherbinin et al. [52] and are applicable to both inland and coastal settings. Building on those recommendations, vulnerability maps focusing on coastal regions would particularly benefit from a better delineation between coastal and inland regions, along with clarification on what is coastal. Location identifiers are also particularly important in coastal vulnerability maps, as they allow for readily visualizing the direction of the sea/ocean, i.e., where the physical hazard comes from. For assessments focused on the coastal beach (e.g., coastal erosion studies), visualizing a long, narrow strip within a larger map would be helpful.

\subsubsection{Policy Relevance}

In our sample, 34 papers declared their work is policy-relevant in a brief ambiguous statement, while 20 papers noted the same but provided additional text to explain this. Only 11 papers provided specific policy recommendations and proposed specific steps or interventions that would reduce coastal vulnerability in the case study locations. The limited effort to provide concrete recommendations in many of the assessments is concerning, especially considering that the majority of coastal vulnerability mapping assessments state that their main goal is to inform policy-making. It is possible that this lack of significant policy discussion is owing to a lack of familiarity among researchers in terms of actual policy needs, the desire of the researchers to remain objective and not be policy-prescriptive, and/or a lack of understanding of exactly how science is integrated into policy-making. This suggests that it would be helpful if researchers undertaking coastal vulnerability mapping assessments had access to simple, clear guidance in terms of how best to present science in order for it to be used in policy-making. While such guidance exists within the peer-reviewed and gray literature [116-118], it is unclear whether coastal researchers are aware of it. There may also be a disconnect in terms of what policy relevance means between different stakeholders and scientists. Some researchers may also believe that as long as they provide good science, the decision-makers will seek it out when needed, so the results do not have to be specially communicated. Lack of policy relevance may also reflect disciplinary bias, whereby researchers from certain fields traditionally not exposed to the policy arena or trained in science communication may not recognize the importance of this discussion or simply deem it unnecessary based on their disciplinary culture.

To evaluate the policy relevance content that followed the coastal vulnerability mapping product, we extracted the policy-relevant text from the examined studies and analyzed it using qualitative analysis software. Unsurprisingly, considering the context of evaluated studies, vulnerability and coastal were the two most frequently occurring words in the policy relevance text (Figure 5). The same applies to the words planning and management, which were also among the most frequently occurring words, indicating that many authors recognize the role of vulnerability assessment maps in helping policy-makers to plan for and manage these risks. Two other frequently occurring words were community and local, suggesting that the community/local scale represents a leading focus of CVMAs, something that is well supported by the relevant literature [119]. Another word that frequently occurred in reviewed studies is climate, indicating that CVMAs recognize the importance of climatic stressors of physical and social vulnerability in coastal settings. The words decision and government were also in the 20 most frequently occurring words, potentially reflecting the notion that the government should be the key actor pursuing policy change to information presented in CVMAs. This science integration is more likely to occur at the local level, considering that local decision-making is generally more responsive to addressing immediate issues in their jurisdictions and available policy mechanisms to respond to challenges in a relatively timely manner (e.g., building and zoning codes, taxes and fees, and public works). 


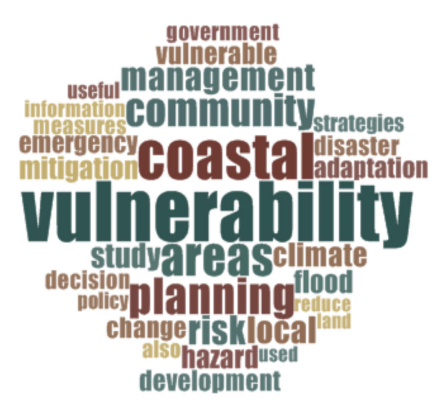

Figure 5. Word frequency of policy-relevant content.

The root keyword coastal occurred in the first order with the expressions: integrated, long-term, zones areas, communities, erosion, flooding/inundation, hazards, disasters, defense, vulnerability, management, planning, and decision-makers. The search for the vulnerability map term with its stemmed words in the policy-relevant text using a narrow context helped identify how authors think vulnerability maps can be used to inform policy. The four main contexts in which this term occurred are:

1. Planning for future hazards before they occur, e.g., "for taking preventive measures to mitigate the disastrous effect of any tsunami in future" [45] and "for the reduction of damage potential by integrating its outputs into spatial and emergency planning" [62];

2. Resource allocation to vulnerable areas, e.g., "to signal which households require the earliest warning possible to protect their goods and evacuate if necessary" [63] and "to provide a useful tool to decision-makers by depicting areas most vulnerable to erosion, coastal flooding, and inundation" [61];

3. Immediate decisions made during hazard events. e.g., "for decision makers as well for the first responders who often make rapid decisions on needed action with limited access to data sources" [73]; and

4. Risk identification, e.g., "as a broad indicator of threats to people living in this coastal zone" [120], "to identify the risks that increase vulnerability to hurricane risk" [63], or "identify the areas that are not able to cope with and recover from the hazard events" [103].

This qualitative analysis of the policy relevance content indicated that the main purpose of mapping outputs is to help decision-makers plan for future hazards (e.g., to reduce damage/negative impacts/losses, better understand and manage risk, and prepare for future events/where changes will occur). They also clearly aim to guide resource allocation by identifying hotspots, prioritizing areas for assistance, signaling the greatest needs, and informing effective use of funds, as well as visualizing multiple future outcomes to support long-term planning. As for the audience for policy recommendations, the authors most commonly referred to domains of spatial and emergency planning, disaster management and mitigation, coastal management, and decision makers.

\section{Conclusions and Recommendations}

As the world's population and urbanization along the coast continue to increase [8], there will be increasing demand for information on how to adapt to future hazards. This information will have to account for the reality that coastal regions have very complex circumstances stemming from distinctive interdependencies and relationships between built, natural, and social environments, all of which shape the significance of coastal settings in terms of environmental and national security, the regional and national economy, and sociocultural and historic determination. Considering coastal system dependencies, it is more likely that flooding will result in cascading events with broader consequences for the region, states, and the nation (i.e., impacts that are more difficult to visualize on a map). For example, floods can result in electrical outages over affected and nonaffected areas, the displacement of population inland, the propagation of toxic wastes in water, and economic impacts far inland. 
In some ways, the coastal zone may seem like a more easily defined geographic unit of analysis, with distinctive spatial boundaries and a well-defined set of hazards (i.e., flooding, storm surge, high winds, etc.). This may indeed be true when it comes to hazard identification, with flooding being the most obvious coastal hazard, irrespective of the cause. However, easy identification and visualization of flood hazards can lead to a focus on that hazard at the expense of other aspects important for a holistic understanding of climate vulnerability, such as other climate stressors and sociodemographic determinants. Similarly, the inclusion of more advanced flood models in CVMAs calls for a high level of technical knowledge that often precludes the inclusion of nonphysical factors that shape coastal vulnerability. Advances in computing and other technologies have been enabling more accurate and complex granular flooding modeling. However, the benefits of these advances are less applicable to the modeling of human/social systems, which are more difficult to capture due to the unique and subjective aspects of people's behaviors, perspectives, and values, as well as the availability of parcel-level socioeconomic data.

This meta-analysis of coastal vulnerability studies suggests that additional efforts are needed to ensure that future coastal vulnerability mapping assessments take a holistic methodological perspective and follow best cartographic practices, which are necessary to effectively influence coastal decision-making. The observed increase in the number of CVMA publications between 2009 and 2016 suggests that there is growing interest and perhaps also growing confidence in this analytical approach. Even though existing CVMAs reflect many different methodologies, with often loose grounding in a single disciplinary designation, it seems many are developed in response to actual need for this type of information in certain geographic areas. Even when these other aspects are considered, coastal vulnerability mapping assessments suffer from the same operationalization challenges when quantifying and displaying spatial differences as experienced by other broader climate vulnerability assessments [52]. Based on the systematic review of CVMA papers, we propose the following seven recommendations for the future development of this field.

CUSTOMIZE THE APPROACH TO MATCH THE CONTEXT. Our analysis shows that the evaluated CVMAs have different objectives, address different issues in diverse coastal settings, use different approaches, and reflect various geospatial contexts. Ultimately, the methodological approach should be aligned with the specific circumstances of the studied locations rather than follow an explicit formula that may not adequately capture data availability, relevant features of the studied location, and the intended audience. Considering this, authors should be explicit about the reasoning behind the applied approach and the selection of variables and datasets, as well as how they represent the conditions of the case study area. Such an approach would enable the transfer of methods to similar geographic contexts or their application to a lower spatial resolution, which would result in comprehensive regional vulnerability estimates [112]. The same transparency of approach should be applied to the discussion about exposure variables to ensure that the strengths and weaknesses of the selected approach are clearly articulated. For example, the text should discuss whether the selected approach will lead to a simplistic representation of flooding and a misinterpretation of what may actually unfold in a given area, especially in the future. It should also address any potential disconnect between the spatial scale of flood exposure and socioeconomic variables, which, depending on the data availability, may vary significantly (e.g., county, municipality, census tract, or block group level versus DEM models represented as the grid cells of different spatial resolution).

Similarly to observations by Nguyen et al. [121], our analysis found a significant diversity of approaches, from conceptual framing to aggregation, and selected metrics, with many attempts to innovate the protocol (e.g., by inclusion of novel variables, clustering in composite elements and justifying, or applying to specific subpopulations such as older adults or sectors such as tourism). This diversity in methodologies and mapping outputs may also stem from the authors' intention of providing a unique identity to their work and, furthermore, asking what are the limits of growth in this field and which domains of CVMAs have the most room to evolve and grow. Cookie-cutter approaches to CVMA, though acceptable for some applications such as comparisons between geographic locations, 
cannot be broadly endorsed by the scientific community since we are striving to refine methodological approaches and tell a more compelling story.

SELECT AN APPROPRIATE SCALE AND DATASETS. The scale alignment should be addressed early on in the coastal vulnerability analysis. More accurate hydrodynamic modeling is generally performed only at local scales and coarse spatial resolution due to computational costs and analytical complexity [122]. However, this is slowly changing with the emergence of models applicable at the regional level and higher spatial resolutions [123]. The former local application of hydrodynamic models can be relevant when justifying adaptation measures that require detailed technical information to support their implementation. Publicly available DEMs like Advanced Spaceborne Thermal Emission and Reflection Radiometer (ASTER GDEM) or Shuttle Radar Topography Mission (SRTM) often represent the easiest approach to delineate flood exposure and are thus widely used in many coastal risk applications [124]. However, the accuracy of DEMs depends on the representation of land features across different spatial scales [125] and is prone to vertical elevation errors that can lead to a major underestimation of the actual flood risk [126]. DEMs have higher vertical accuracy in low-lying coastal plains with elevations below $20 \mathrm{~m}$ with SRTM performing better than the ASTER GDEM [126]. New products seek to correct global DEMs such as SRTM through the use of artificial neural network models [127] or satellite altimetry estimates [128].

The inclusion of indicators in CVMA is likely driven by the convenience of obtaining data and by familiarity with the methodology observed in a broader field of climate vulnerability mapping [35]. Most coastal vulnerability mapping studies follow flexible approaches that allow for the inclusion of different variables. The one major exception is the Coastal Vulnerability Index, which conceptually prescribes the standard selection of geophysical variables and the procedure for their aggregation. This consistency of approach is expected, considering it is generally easier to obtain and manage geophysical data than to capture social data, especially at a more granular level. Even though most studies use top-down approaches (e.g., select an area with known coastal flooding challenges, assess it, and provide the policy recommendations), Ramieri et al. [129] suggest that the study design should instead be driven by its capacity to inform different stages of the decision-making process (e.g., risk identification versus the selection of adaptation strategies).

FOLLOW CARTOGRAPHIC BEST PRACTICES. Considering that most CVMAs culminate with a vulnerability map, special attention should be paid to this final product to ensure that it meets the optimal cartographic standards. Otherwise, the mapping effort could represent a missed opportunity to effectively communicate results to the target audience. Authors should spend adequate time on map design to ensure that they contain all the elements necessary for comprehension, such as sufficient resolution, all labels necessary for accurate interpretation, and the necessary amount of location identifiers. Furthermore, the aggregation of multiple composite indices may obscure their individual contribution on the overall vulnerability [35] and supporting maps showing individual components or key drivers of vulnerability may be useful to communicate drivers of vulnerability. In line with the last recommendation (below), it is recommended to incorporate depictions of underlying uncertainties in the data into maps [52,130]. In addition, static maps, such as those developed in the studies examined here, are increasingly competing with the online interactive maps and visualization tools such as Surging Seas (Climate Central), Sea Level Rise Viewer (NOAA), Massachusetts Sea Level Rise and Coastal Flooding Viewer, and may other regional and local efforts. This puts even more pressure on CVMA developers to consolidate and refine cartographic standards and map design to communicate the vulnerability messages without having an option to adjust settings, zoom in, or explore individual mapping features. Providing a supplemental narrative could be a compelling way to tell a story about the map that would be otherwise self-derived via explorations using interactive CVA maps and tools.

TAKE A HOLISTIC PERSPECTIVE. Seamless integration of the many factors that define coastal vulnerability can be difficult considering the complexities present in coastal settings, and in defining vulnerability more broadly. Even though it may be challenging to account for all the factors that 
shape the vulnerability of coastal places, transparency about what individual variables tell us about systems of interest is vital, even if merely textual. Inclusion of interdisciplinary perspectives in CVMAs can ensure that assessments more holistically capture various location-specific physical and socioeconomic vulnerabilities and lead to more policy-relevant outcomes. As such, coastal vulnerability mapping products are more likely to influence policy if they reflect the actual circumstances in studied locations and are cognizant of their dependencies and interactions (e.g., by inclusion of both geophysical and socioeconomic data). Based on the literature review of coastal vulnerability assessments, Bevacqua et al. [36] observed a convergence of ecological, physical, and socioeconomic domains in CVA studies, while Nguyen et al. [121] noted the rise of "second-generation" assessments that use novel approaches to integrate nonphysical drivers into assessments. While such integration can be challenging, it can increase the usefulness of vulnerability maps as tools for understanding the complexity of coupled natural and human dimensions, and thus for informing decision-making. The usefulness of CVMAs would be further improved by the inclusion of strategies to address the vulnerabilities identified though the mapping analysis; however, the identification of such options can be difficult to justify and may require a higher level of expertise [129].

CONSIDER CAREFULLY THE CONTRIBUTION TO POLICY-MAKING. The key rationale offered by the majority of the CVMA studies examined here is to improve decision-making and planning for future hazards. Many studies seem to assume the information they provide would inform policy processes once made available, even though the literature has clearly shown this not to be true [131]. Therefore, it is important to identify what type of information and in what delivery format planners and other practitioners need to ensure that the CVMA results can be translated into meaningful policy actions. Furthermore, CVMAs that provide integrated community assessments and help practitioners understand the primary causes of vulnerability are vital prerequisites for the selection of appropriate adaptation solutions [132]. Coastal management and policy would benefit from vulnerability assessments that attempt to capture the complexities and dynamics of coastal systems; however, such policy contributions should be clearly defined early on in the studies to provide the context for analysis [129]. It will also be important to discuss the alignment between the geographic scale of vulnerability assessments and the possible policy interventions and programs designed to address these vulnerabilities to ensure that results can be translated into meaningful policy actions on the appropriate municipal or regional level and eventually implemented. As mentioned before, the extent and spatial distribution of coastal hazards rarely matches the administrative boundaries. However, relying on administrative units for vulnerability analysis is more likely to yield information useful for adaptation and resilience planning, regardless of the scale and scope of the hazard. If the focus is on a broader or regional hazard that spans multiple administrative units, then using administrative units may help with comparing and synchronizing policy responses across multiple municipalities to achieve a more uniform level of adaptation and resilience. If the focus is on a single administrative unit that is only partially impacted by coastal hazards, it is likely that indirect impacts will still be felt across the whole municipality, which will then be primarily responsible for addressing this issue. Therefore, it is important to identify the audience for CVMAs, especially if they offer specific policy recommendations (e.g., structural interventions or programs to reduce social vulnerability). Lastly, it is important to be transparent about the methodological and mapping constraints and how they may influence policy decisions. This will help avoid misinterpretation of the results and/or a misalignment between results and decisions, which could result in ineffective policies and even eventually lead to maladaptation. For example, the recognition that vulnerability assessments represent only conceptual means and not absolute truths can encourage local governments to include them in decision-making while still ensuring that policy decisions are based on information that is not violating the legal right to equal protection [133]. This is especially important when evaluating social vulnerability variables such as ethnicity and gender.

INCLUDE PARTICIPATORY INPUT, WHERE APPROPRIATE. Considering that coastal settings are defined by complex and constantly evolving circumstances, participatory input from 
experts and other stakeholders could help capture (and appropriately frame) some of the contextual factors that shape the identity of coastal places but are not easily discernible from secondary data. For example, the inclusion of qualitative considerations and weighting of individual variables would ensure that metrics are more accurately aligned with the actual circumstances on the ground. Participatory input can also improve the reliability and transparency of results and increase confidence in mapping products among policy-makers. Inclusion of local knowledge and public contribution can also promote public support for new/revised policy decisions [36]. However, participatory input without an adequate level of detail on how it was collected and the scientific rigor of the data collection protocol may be counterproductive, indicating possible subjective bias in the study. Inclusion of social scientists on the CVMA development team would be beneficial to ensure that data collection from human subjects has the appropriate quality controls and institutional review board (IRB) approval. Using strategies such as participatory modeling or mapping can ensure that the final products reflect diverse perspectives and experiences and may more accurately portray conditions in the assessment area [132]. Working with human subjects, using adequate protocols, and researching ethics principles may be more time-consuming, costly, and require special expertise, but may be worth doing considering the benefits for the policy relevance and quality of CVMAs. However, participatory input may be more important (and feasible) for studies conducted at the local scale than at larger scales.

ADEQUATELY ADDRESS UNCERTAINTY AND VALIDATION. Addressing uncertainty and validation within CVMA studies is important to improve the legitimacy of this body of literature in decision-making. Validation tells us whether the assessment is measuring what it is supposed to, and, as such, increases the legitimacy of the findings, especially for use in decision-making. However, it may be difficult and time-consuming to validate the CVMA results, especially considering that vulnerability represents a concept that is emergent and depends on the internal and external stimuli and stressors in communities. However, validation can be achieved, for example, by comparing the results derived by experts and those estimated by stakeholders or through sensitivity analysis (whereby indicators are dropped, weights are changed, or aggregation methods altered to assess the robustness of results to assumptions). As for uncertainty, Preston et al. [35] note that inconsistency in the representation of uncertainty in vulnerability assessments can cast doubt on the precision of the findings and limit their use in policy. On the other hand, Woodroff et al. [81] suggest that the inclusion of uncertainty in vulnerability assessments should depend on the target audience and assessment purpose, as otherwise the inclusion of additional information (e.g., via the inclusion of scenarios or cartographic elements) may lead to information overload and distract from the key study results. In the latter cases, it may be best to include the discussion of uncertainty and validation in an appendix, so interested audiences can find the information but it is not overwhelming or distracting.

Supplementary Materials: The following are available online at http://www.mdpi.com/2071-1050/12/7/2822/s1: (1) Literature sample; (2) Coding approach; (3) Summary of methodologies used in reviewed literature.

Author Contributions: Conceptualization, A.B. and G.R.; Methodology, A.B., G.R., A.A., and A.d.S.; Formal analysis, A.B., R.G. and A.A.; Design and preparation of visual outputs, A.B.; Interpretation and writing-First draft preparation, A.B. and G.R.; Later drafts writing-Review and editing, A.B., A.A., A.d.S.; Visualization, A.B.; Supervision, A.B.; Funding acquisition, A.d.S. All authors have read and agreed to the published version of the manuscript.

Funding: This research was funded by the National Socio-Environmental Synthesis Center (SESYNC) under funding received from the National Science Foundation, grant number DBI-1639145. A.D. wishes to acknowledge support under NASA contract NNG13HQ04C for the continued operation of the Socioeconomic Data and Applications Center (SEDAC).

Acknowledgments: Open access publishing was supported by the Virginia Tech's Open Access Subvention Fund.

Conflicts of Interest: The authors declare no conflict of interest.

Dedication: This paper is dedicated to the memory of Guillaume Rohat, the second author on this paper and a wonderful colleague and outstanding person, who unexpectedly passed away in October 2019. His intellectual contribution to and enthusiasm for this study were instrumental to the development of this paper. 


\section{References}

1. CIESIN: Center for International Earth Science Information Network, Columbia University. Low Elevation Coastal Zone (LECZ) Urban-Rural Population and Land Area Estimates, Version 2; NASA Socioeconomic Data and Applications Center (SEDAC): Palisades, NY, USA, 2013.

2. CIESIN: Center for International Earth Science Information Network, Columbia University. National Aggregates of Geospatial Data Collection: Population, Landscape, And Climate Estimates, Version 3 (PLACE III); NASA Socioeconomic Data and Applications Center (SEDAC): Palisades, NY, USA, 2012.

3. de Sherbinin, A.; Levy, M.; Adamo, S.; MacManus, K.; Yetman, G.; Mara, V.; Razafindrazay, L.; Goodrich, B.; Srebotnjak, T.; Aichele, C. Migration and risk: Net migration in marginal ecosystems and hazardous areas. Environ. Res. Lett. 2012, 7, 045602. [CrossRef]

4. Small, C.; Nicholls, R.J. A global analysis of human settlement in coastal zones. J. Coast. Res. 2003, 584-599. [CrossRef]

5. Nicholls, R.J.; Wong, P.P.; Burkett, V.; Codignotto, J.; Hay, J.; McLean, R.; Ragoonaden, S.; Woodroffe, C.D.; Abuodha, P.A.O.; Arblaster, J.; et al. Coastal Systems and Low-Lying Areas; University of Wollongong: Wollongong, Australia, 2007.

6. McGranahan, G.; Balk, D.; Anderson, B. The rising tide: Assessing the risks of climate change and human settlements in low elevation coastal zones. Environ. Urban. 2007, 19, 17-37. [CrossRef]

7. Smith, K. We are seven billion. Nat. Clim. Chang. 2011, 1, 331-335. [CrossRef]

8. Neumann, B.; Vafeidis, A.T.; Zimmermann, J.; Nicholls, R.J. Future coastal population growth and exposure to sea-level rise and coastal flooding-a global assessment. PLoS ONE 2015, 10, e0118571. [CrossRef]

9. Merkens, J.-L.; Reimann, L.; Hinkel, J.; Vafeidis, A.T. Gridded population projections for the coastal zone under the Shared Socioeconomic Pathways. Glob. Planet. Chang. 2016, 145, 57-66. [CrossRef]

10. De Sherbinin, A.; Schiller, A.; Pulsipher, A. The vulnerability of global cities to climate hazards. Environ. Urban. 2007, 19, 39-64. [CrossRef]

11. Tibbetts, J. Coastal cities: Living on the edge. Environ. Health Perspect. 2002, 110, A674-A681. [CrossRef]

12. Hanson, S.; Nicholls, R.; Ranger, N.; Hallegatte, S.; Corfee-Morlot, J.; Herweijer, C.; Chateau, J. A global ranking of port cities with high exposure to climate extremes. Clim. Chang. 2011, 104, 89-111. [CrossRef]

13. Bhatia, K.; Vecchi, G.; Murakami, H.; Underwood, S.; Kossin, J. Projected response of tropical cyclone intensity and intensification in a global climate model. J. Clim. 2018, 31, 8281-8303. [CrossRef]

14. Bhatia, K.T.; Vecchi, G.A.; Knutson, T.R.; Murakami, H.; Kossin, J.; Dixon, K.W.; Whitlock, C.E. Recent increases in tropical cyclone intensification rates. Nat. Commun. 2019, 10, 635. [CrossRef] [PubMed]

15. Kim, H.-S.; Vecchi, G.A.; Knutson, T.R.; Anderson, W.G.; Delworth, T.L.; Rosati, A.; Zeng, F.; Zhao, M. Tropical cyclone simulation and response to $\mathrm{CO}_{2}$ doubling in the GFDL CM2.5 high-resolution coupled climate model. J. Clim. 2014, 27, 8034-8054. [CrossRef]

16. Knutson, T.R.; McBride, J.L.; Chan, J.; Emanuel, K.; Holland, G.; Landsea, C.; Held, I.; Kossin, J.P.; Srivastava, A.K.; Sugi, M. Tropical cyclones and climate change. Nat. Geosci. 2010, 3, 157-163. [CrossRef]

17. Villarini, G.; Vecchi, G.A. Projected increases in North Atlantic tropical cyclone intensity from CMIP5 models. J. Clim. 2013, 26, 3231-3240. [CrossRef]

18. Nicholls, R.J.; Cazenave, A. Sea-level rise and its impact on coastal zones. Science 2010, 328, 1517-1520. [CrossRef]

19. Holland, G.; Bruyère, C.L. Recent intense hurricane response to global climate change. Clim. Dyn. 2014, 42, 617-627. [CrossRef]

20. Moftakhari, H.R.; AghaKouchak, A.; Sanders, B.F.; Matthew, R.A. Cumulative hazard: The case of nuisance flooding. Earth Future 2017, 5, 214-223. [CrossRef]

21. Karegar, M.A.; Dixon, T.H.; Malservisi, R.; Kusche, J.; Engelhart, S.E. Nuisance flooding and relative sea-level rise: The importance of present-day land motion. Sci. Rep. 2017, 7. [CrossRef] [PubMed]

22. Wong, P.P.; Losada, I.J.; Gattuso, J.-P.; Hinkel, J.; Khattabi, A.; McInnes, K.L.; Saito, Y.; Sallenger, A. Coastal systems and low-lying areas. Clim. Chang. 2014, 2104, 361-409.

23. Jongman, B.; Ward, P.J.; Aerts, J.C. Global exposure to river and coastal flooding: Long term trends and changes. Glob. Environ. Chang. 2012, 22, 823-835. [CrossRef]

24. NOAA: National Oceanic and Atmospheric Administration. Hurricanes Costs. Available online: https: //coast.noaa.gov/states/fast-facts/hurricane-costs.html (accessed on 23 May 2019). 
25. Hsiang, S.M.; Jina, A.S. The Causal Effect of Environmental Catastrophe on Long-Run Economic Growth: Evidence from 6700 Cyclones; National Bureau of Economic Research: Cambridge, MA, USA, 2014.

26. Groen, J.; Kutzbach, M.; Polivka, A. Storms and jobs: The effect of hurricanes on individuals' employment and earnings over the long term. In US Census Bureau Center for Economic Studies Paper No. CES-WP-15-21R; U.S. Census Bureau, Center for Economic Studies 2K132B: Washington, DC, USA, 2015.

27. Füssel, H.-M.; Klein, R.J. Climate change vulnerability assessments: An evolution of conceptual thinking. Clim. Chang. 2006, 75, 301-329. [CrossRef]

28. Eriksen, S.H.; Kelly, P.M. Developing credible vulnerability indicators for climate adaptation policy assessment. Mitig. Adapt Strateg. Glob. Chang. 2007, 12, 495-524. [CrossRef]

29. Füssel, H.-M. Vulnerability: A generally applicable conceptual framework for climate change research. Glob. Environ. Chang. 2007, 17, 155-167. [CrossRef]

30. Hinkel, J. "Indicators of vulnerability and adaptive capacity": Towards a clarification of the science-policy interface. Glob. Environ. Chang. 2011, 21, 198-208. [CrossRef]

31. Janssen, M.; Ostrom, E. Resilience, vulnerability, and adaptation: A cross-cutting theme of the International Human Dimensions Programme on Global Environmental Change. Glob. Environ. Chang. 2006, 16, $237-239$. [CrossRef]

32. Eakin, H.; Bojórquez-Tapia, L.A. Insights into the composition of household vulnerability from multicriteria decision analysis. Glob. Environ. Chang. 2008, 18, 112-127. [CrossRef]

33. Klein, R.J. Identifying countries that are particularly vulnerable to the adverse effects of climate change: An academic or a political challenge? Carbon Clim. Law Rev. 2009, 3, 284-291. [CrossRef]

34. Alwang, J.; Siegel, P.B.; Jorgensen, S.L. Vulnerability: A view from different disciplines. In Social Protection Discussion Paper Series; The World Bank: Washington, DC, USA, 2001.

35. Preston, B.L.; Yuen, E.J.; Westaway, R.M. Putting vulnerability to climate change on the map: A review of approaches, benefits, and risks. Sustain. Sci. 2011, 6, 177-202. [CrossRef]

36. Bevacqua, A.; Yu, D.; Zhang, Y. Coastal vulnerability: Evolving concepts in understanding vulnerable people and places. Environ. Sci. Policy 2018, 82, 19-29. [CrossRef]

37. Downing, T.E.; Butterfield, R.; Cohen, S.; Huq, S.; Moss, R.; Rahman, A.; Sokona, Y.; Stephen, L. Vulnerability indices: Climate change impacts and adaptation. In UNEP Policy Series; UNEP: Nairobi, Kenya, 2001.

38. Allen, K. Vulnerability reduction and the community-based approach. In Natural Disaster and Development in a Globalizing World; Taylor \& Francis Group: New York, NY, USA, 2003.

39. Brooks, N. Vulnerability, risk and adaptation: A conceptual framework. Tyndall Cent. Clim. Chang. Res. Work. Pap. 2003, 38, 1-16.

40. Eakin, H.; Luers, A.L. Assessing the vulnerability of social-environmental systems. Annu. Rev. Environ. Resour. 2006, 31, 365-394. [CrossRef]

41. Vincent, K. Creating an index of social vulnerability to climate change for Africa. Tyndall Cent. Clim. Chang. Res. Work. Pap. 2004, 56, 1-50.

42. Füssel, H.-M. Review and Quantitative Analysis of Indices of Climate Change Exposure, Adaptive Capacity, Sensitivity, and Impacts; The World Bank: Washington, DC, USA, 2010.

43. Fellmann, T. The assessment of climate change-related vulnerability in the agricultural sector: Reviewing conceptual frameworks. Build. Resil. Adapt. Clim. Chang. Agric. Sec. 2012, 23, 37.

44. Hinkel, J.; Bisaro, A. Methodological choices in solution-oriented adaptation research: A diagnostic framework. Reg. Environ. Chang. 2016, 16, 7-20. [CrossRef]

45. Ajin, A.S.; Jacob, M.K.; Vinod, P.G. Tsunami vulnerability mapping using remote sensing and GIS techniques: A case study of Kollam District, Kerala, India. Iran. J. Earth Sci. 2014, 6, 44-51.

46. Islam, M.A.; Mitra, D.; Dewan, A.; Akhter, S.H. Coastal multi-hazard vulnerability assessment along the Ganges deltaic coast of Bangladesh-A geospatial approach. Ocean Coast. Manag. 2016, 127, 1-15. [CrossRef]

47. Dwarakish, G.S.; Vinay, S.A.; Natesan, U.; Asano, T.; Kakinuma, T.; Venkataramana, K.; Pai, B.J.; Babita, M.K. Coastal vulnerability assessment of the future sea level rise in Udupi coastal zone of Karnataka state, west coast of India. Ocean Coast. Manag. 2009, 52, 467-478. [CrossRef]

48. Gornitz, V.M. Vulnerability of the East Coast, USA to future sea level rise. J. Coast. Res. 1990, 9, $201-237$.

49. Gornitz, V.M.; Daniels, R.C.; White, T.W.; Birdwell, K.R. The development of a coastal risk assessment database: Vulnerability to sea-level rise in the US Southeast. J. Coast. Res. 1994, 12, 327-338. 
50. de Sherbinin, A.D.; Apotsos, A.; Chevrier, J. Mapping the future: Policy applications of climate vulnerability mapping in West Africa. Geogr. J. 2017, 183, 414-425. [CrossRef]

51. Kienberger, S.; Blaschke, T.; Zaidi, R.Z. A framework for spatio-temporal scales and concepts from different disciplines: The 'vulnerability cube. ' Nat. Hazards 2013, 68, 1343-1369. [CrossRef]

52. de Sherbinin, A.; Bukvic, A.; Rohat, G.; Gall, M.; McCusker, B.; Preston, B.; Apotsos, A.; Fish, C.; Kienberger, S.; Muhonda, P. Climate vulnerability mapping: A systematic review and future prospects. Wiley Interdiscip. Rev. Clim. Chang. 2019, 10, e600. [CrossRef]

53. Ellis, K.N.; Sylvester, L.M.; Trepanier, J.C. Spatiotemporal patterns of extreme hurricanes impacting US coastal cities. Nat. Hazards 2015, 75, 2733-2749. [CrossRef]

54. Sweet, W.W.V.; Dusek, G.; Obeysekera, J.T.B.; Marra, J.J. Patterns and Projections of High Tide Flooding along the US Coastline Using a Common Impact Threshold; National Oceanic and Atmospheric Administration: Silver Spring, MD, USA, 2018.

55. Raymond, C.; Mankin, J.S. Assessing present and future coastal moderation of extreme heat in the Eastern United States. Environ. Res. Lett. 2019, 14, 114002. [CrossRef]

56. Desai, V.K.; Wagle, S.; Rathi, S.K.; Patel, U.; Desai, H.S.; Khatri, K. Effect of ambient heat on all-cause mortality in the coastal city of Surat, India. Curr. Sci. 2015, 1680-1686.

57. Kunreuther, H.; Wachter, S.M.; Kousky, C.; LaCour-Little, M. Flood Risk and the US Housing Market; Social Science Research Network (SSRN): Rochester, NY, USA, 2019.

58. de Sherbinin, A.; Bardy, G. Social vulnerability to floods in two coastal megacities: New York City and Mumbai. Vienna Yearb. Popul. Res. 2015, 131-165. [CrossRef]

59. Chakrabarti, P.; Frye, M. A mixed-methods framework for analyzing text data: Integrating computational techniques with qualitative methods in demography. Demogr. Res. 2017, 37, 1351-1382. [CrossRef]

60. Wattenberg, M.; Viégas, F.B. The word tree, an interactive visual concordance. IEEE Trans. Vis. Comput. Gr. 2008, 14, 1221-1228. [CrossRef]

61. Kunte, P.D.; Jauhari, N.; Mehrotra, U.; Kotha, M.; Hursthouse, A.S.; Gagnon, A.S. Multi-hazards coastal vulnerability assessment of Goa, India, using geospatial techniques. Ocean Coast. Manag. 2014, 95, $264-281$. [CrossRef]

62. Akukwe, T.I.; Ogbodo, C. Spatial analysis of vulnerability to flooding in Port Harcourt metropolis, Nigeria. SAGE Open 2015, 5, 2158244015575558. [CrossRef]

63. Krishnamurthy, P.K.; Fisher, J.B.; Johnson, C. Mainstreaming local perceptions of hurricane risk into policymaking: A case study of community GIS in Mexico. Glob. Environ. Chang. 2011, 21, 143-153. [CrossRef]

64. Lee, Y.-J.; Lin, S.-C.; Chen, C.-C. Mapping cross-boundary climate change vulnerability-Case study of the Hualien and Taitung Area, Taiwan. Sustainability 2016, 8, 64. [CrossRef]

65. Mendoza, M.E.T.; Naret, H.; Ballaran, V.G.; Arias, J.K.B. Assessing vulnerability to climate change impacts in Cambodia, the Philippines and Vietnam: An analysis at the commune and household level. J. Environ. Sci. Manag. 2014, 17, 78-91.

66. Kane, H.H.; Fletcher, C.H.; Frazer, L.N.; Anderson, T.R.; Barbee, M.M. Modeling sea-level rise vulnerability of coastal environments using ranked management concerns. Clim. Chang. 2015, 131, 349-361. [CrossRef]

67. Preston, B.L.; Smith, T.F.; Brooke, C.; Gorddard, R.; Measham, T.G.; Withycombe, G.; Beveridge, B.; Morrison, C.; McInnes, K.; Abbs, D. Mapping Climate Change Vulnerability in the Sydney Coastal Councils Group; Sydney Coastal Councils Group: Sydney, Australia, 2008.

68. Roy, D.C.; Blaschke, T. Spatial vulnerability assessment of floods in the coastal regions of Bangladesh. Geomat. Nat. Hazards Risk 2015, 6, 21-44. [CrossRef]

69. Weis, S.W.M.; Agostini, V.N.; Roth, L.M.; Gilmer, B.; Schill, S.R.; Knowles, J.E.; Blyther, R. Assessing vulnerability: An integrated approach for mapping adaptive capacity, sensitivity, and exposure. Clim. Chang. 2016, 136, 615-629. [CrossRef]

70. Trzaska, S.A. Climate Change Vulnerability Assessment in Mangrove Regions of Sierra Leone: Long Version; Report; USAID West Africa Biodiversity and Climate Change (WA BiCC) Project: Washington, DC, USA, 2017.

71. Wang, Y.; Zhao, L.; Yang, D.; Moses, M. GIS-based climate change vulnerability mapping at the urban scale: A case study of Shanghai metropolitan area in China. Int. J. Environ. Stud. 2015, 72, 1002-1016. [CrossRef]

72. Bathi, J.R.; Das, H.S. Vulnerability of coastal communities from storm surge and flood disasters. Int. J. Environ. Res. Public Health 2016, 13, 239. [CrossRef] 
73. Reams, M.A.; Lam, N.S.; Baker, A. Measuring capacity for resilience among coastal counties of the US Northern Gulf of Mexico Region. Am. J. Clim. Chang. 2012, 1, 194. [CrossRef]

74. Baum, S.; Horton, S.; Low Choy, D.; Gleeson, B. Climate change, health impacts and urban adaptability: case study of Gold Coast City. Res. Monogr. 2009, 11, 68.

75. Creach, A.; Pardo, S.; Guillotreau, P.; Mercier, D. The use of a micro-scale index to identify potential death risk areas due to coastal flood surges: Lessons from Storm Xynthia on the French Atlantic coast. Nat. Hazards 2015, 77, 1679-1710. [CrossRef]

76. Kleinosky, L.R.; Yarnal, B.; Fisher, A. Vulnerability of Hampton Roads, Virginia to storm-surge flooding and sea-level rise. Nat. Hazards 2007, 40, 43-70. [CrossRef]

77. Eckert, S.; Jelinek, R.; Zeug, G.; Krausmann, E. Remote sensing-based assessment of tsunami vulnerability and risk in Alexandria, Egypt. Appl. Geogr. 2012, 32, 714-723. [CrossRef]

78. Lein, J.K.; Abel, L.E. Hazard vulnerability assessment: How well does nature follow our rules? Environ. Hazards 2010, 9, 147-166. [CrossRef]

79. Mahapatra, M.; Ratheesh, R.; Rajawat, A.S. Storm surge vulnerability assessment of Saurashtra coast, Gujarat, using GIS techniques. Nat. Hazards 2017, 86, 821-831. [CrossRef]

80. Woodruff, S.; BenDor, T.K.; Strong, A.L. Fighting the inevitable: Infrastructure investment and coastal community adaptation to sea level rise. Syst. Dyn. Rev. 2018, 34, 48-77. [CrossRef]

81. Strauss, B.H.; Ziemlinski, R.; Weiss, J.L.; Overpeck, J.T. Tidally adjusted estimates of topographic vulnerability to sea level rise and flooding for the contiguous United States. Environ. Res. Lett. 2012, 7, 014033. [CrossRef]

82. Brown, S.; Nicholls, R.J.; Hanson, S.; Brundrit, G.; Dearing, J.A.; Dickson, M.E.; Gallop, S.L.; Gao, S.; Haigh, I.D.; Hinkel, J. Shifting perspectives on coastal impacts and adaptation. Nat. Clim. Chang. 2014, 4, 752. [CrossRef]

83. Wahl, T.; Jain, S.; Bender, J.; Meyers, S.D.; Luther, M.E. Increasing risk of compound flooding from storm surge and rainfall for major US cities. Nat. Clim. Chang. 2015, 5, 1093-1097. [CrossRef]

84. Geoghegan, K.M.; Fitzpatrick, P.; Kolar, R.L.; Dresback, K.M. Evaluation of a synthetic rainfall model, P-CLIPER, for use in coastal flood modeling. Nat. Hazards 2018, 92, 699-726. [CrossRef]

85. Gallien, T.W.; Kalligeris, N.; Delisle, M.-P.C.; Tang, B.-X.; Lucey, J.T.; Winters, M.A. Coastal flood modeling challenges in defended urban backshores. Geosciences 2018, 8, 450. [CrossRef]

86. Barnard, P.L.; Erikson, L.H.; Foxgrover, A.C.; Hart, J.A.F.; Limber, P.; O’Neill, A.C.; van Ormondt, M.; Vitousek, S.; Wood, N.; Hayden, M.K. Dynamic flood modeling essential to assess the coastal impacts of climate change. Sci. Rep. 2019, 9, 1-13.

87. Tebaldi, C.; Strauss, B.H.; Zervas, C.E. Modelling sea level rise impacts on storm surges along US coasts. Environ. Res. Lett. 2012, 7, 014032. [CrossRef]

88. Wolters, M.L.; Kuenzer, C. Vulnerability assessments of coastal river deltas-categorization and review. J. Coast. Conserv. 2015, 19, 345-368. [CrossRef]

89. Hagenlocher, M.; Renaud, F.G.; Haas, S.; Sebesvari, Z. Vulnerability and risk of deltaic social-ecological systems exposed to multiple hazards. Sci. Total Environ. 2018, 631, 71-80. [CrossRef]

90. Hoque, M.A.-A.; Phinn, S.; Roelfsema, C. A systematic review of tropical cyclone disaster management research using remote sensing and spatial analysis. Ocean Coast. Manag. 2017, 146, 109-120. [CrossRef]

91. Nguyen, T.T.; Woodroffe, C.D. Assessing relative vulnerability to sea-level rise in the western part of the Mekong River Delta in Vietnam. Sustain. Sci. 2016, 11, 645-659. [CrossRef]

92. Cutter, S.L.; Boruff, B.J.; Lynn Shirley, W. Social Vulnerability to Environmental Hazards. Soc. Sci. Q. 2003, 84, 242-261. [CrossRef]

93. Hung, L.-S.; Wang, C.; Yarnal, B. Vulnerability of families and households to natural hazards: A case study of storm surge flooding in Sarasota County, Florida. Appl. Geogr. 2016, 76, 184-197. [CrossRef]

94. Toda, L.; Orduña, J.R.; Lasco, R.D.; Santos, C.T. Assessing and mapping barangay level social vulnerability of Tacloban City and Ormoc City to climate-related hazards. Clim. Disaster Dev. J. 2015. [CrossRef]

95. Dube, S.K.; Mazumder, T.; Das, A. An approach to vulnerability assessment for tropical cyclones: A case study of a coastal district in West Bengal. ITPI J. 2006, 3, 15-27.

96. Dinh, Q.; Balica, S.; Popescu, I.; Jonoski, A. Climate change impact on flood hazard, vulnerability and risk of the Long Xuyen Quadrangle in the Mekong Delta. Int. J. River Basin Manag. 2012, 10, 103-120. [CrossRef]

97. Thieler, E.R.; Hammar-Klose, E.S. National Assessment of Coastal Vulnerability to Sea-Level Rise; U.S. Geological Survey Open-File Report 99-593; U.S. Geological Survey: Woods Hole, MA, USA, 1999. 
98. Boruff, B.J.; Emrich, C.; Cutter, S.L. Erosion hazard vulnerability of US coastal counties. J. Coast. Res. 2005, 932-942. [CrossRef]

99. Mavromatidi, A.; Briche, E.; Claeys, C. Mapping and analyzing socio-environmental vulnerability to coastal hazards induced by climate change: An application to coastal Mediterranean cities in France. Cities 2018, 72, 189-200. [CrossRef]

100. Islam, M.A.; Hossain, M.S.; Murshed, S. Assessment of coastal vulnerability due to sea level change at Bhola Island, Bangladesh: Using geospatial techniques. J. Indian Soc. Remote Sens. 2015, 43, 625-637. [CrossRef]

101. Basheer Ahammed, K.K.; Mahendra, R.S.; Pandey, A.C. Coastal vulnerability assessment for Eastern Coast of India, Andhra Pradesh by using geo-spatial technique. Geoinform. Geostat. Overv. 2016, 4. [CrossRef]

102. Joevivek, V.; Saravanan, S.; Chandrasekar, N. Coastal vulnerability and shoreline changes for southern tip of India-Remote sensing and GIS approach. J. Earth Sci. Clim. Chang. 2013, 4, 144.

103. Mazumdar, J.; Paul, S.K. Socioeconomic and infrastructural vulnerability indices for cyclones in the eastern coastal states of India. Nat. Hazards 2016, 82, 1621-1643. [CrossRef]

104. ESPON. Climate Change and Territorial Effects on Regions and Local Economies; ESPON Applied Research; European Commission: Brussels, Belgium, 2013.

105. Mani Murali, R.; Ankita, M.; Amrita, S.; Vethamony, P. Coastal vulnerability assessment of Puducherry coast, India, using the analytical hierarchical process. Nat. Hazards Earth Syst. Sci. 2013, 13, 3291-3311. [CrossRef]

106. Li, M.; Wu, W.; Wang, J.; Che, Z.; Xie, Y. Simulating and mapping the risk of surge floods in multiple typhoon scenarios: A case study of Yuhuan County, Zhejiang Province, China. Stoch. Environ. Res. Risk Assess. 2017, 31, 645-659. [CrossRef]

107. Lam, N.S.-N.; Qiang, Y.; Arenas, H.; Brito, P.; Liu, K. Mapping and assessing coastal resilience in the Caribbean region. Cartogr. Geogr. Inf. Sci. 2015, 42, 315-322. [CrossRef]

108. Fekete, A. Validation of a social vulnerability index in context to river-floods in Germany. Nat. Hazards Earth Syst. Sci. 2009, 9. [CrossRef]

109. Molinari, D.; De Bruijn, K.M.; Castillo-Rodríguez, J.T.; Aronica, G.T.; Bouwer, L.M. Validation of flood risk models: Current practice and possible improvements. Int. J. Disaster Risk Reduct. 2019, 33, 441-448. [CrossRef]

110. Krishnan, P.; Ananthan, P.S.; Purvaja, R.; Jeevamani, J.J.J.; Infantina, J.A.; Rao, C.S.; Anand, A.; Mahendra, R.S.; Sekar, I.; Kareemulla, K. Framework for mapping the drivers of coastal vulnerability and spatial decision making for climate-change adaptation: A case study from Maharashtra, India. Ambio 2019, 48, 192-212. [CrossRef]

111. NOAA: National Oceanic and Atmospheric Administration. Coastal County Definitions. Available online: https://coast.noaa.gov/data/digitalcoast/pdf/qrt-coastal-county-definitions.pdf (accessed on 23 May 2019).

112. Barman, N.K.; Chatterjee, S.; Paul, A.K. Estimate the coastal vulnerability in the Balasore Coast of India: A statistical approach. Model. Earth Syst. Environ. 2016, 2, 20. [CrossRef]

113. Muler, M.; Bonetti, J. An integrated approach to assess wave exposure in coastal areas for vulnerability analysis. Mar. Geod. 2014, 37, 220-237. [CrossRef]

114. Snoussi, M.; Niazi, S.; Khouakhi, A.; Raji, O. Climate change and sea-level rise: Agis-based vulnerability and impact assessment, the case of the Moroccan coast. In Geomatic Solutions for Coastal Environments; Nova Science Publishers Inc.: Hauppauge, NY, USA, 2010; pp. 275-310.

115. Tate, E.; Cutter, S.L.; Berry, M. Integrated multihazard mapping. Environ. Plan. B Plan. Des. 2010, 37, 646-663. [CrossRef]

116. Vogel, C.; Moser, S.C.; Kasperson, R.E.; Dabelko, G.D. Linking vulnerability, adaptation and resilience science to practice: Pathways, players and partnerships. In Integrating Science and Policy; Routledge: London, UK, 2012; pp. 117-148.

117. Dilling, L.; Lemos, M.C. Creating usable science: Opportunities and constraints for climate knowledge use and their implications for science policy. Glob. Environ. Chang. 2011, 21, 680-689. [CrossRef]

118. NASEM. Communicating Science Effectively: A Research Agenda; The National Academies Press: Washington, DC, USA, 2017.

119. Norris, F.H.; Stevens, S.P.; Pfefferbaum, B.; Wyche, K.F.; Pfefferbaum, R.L. Community resilience as a metaphor, theory, set of capacities, and strategy for disaster readiness. Am. J. Community Psychol. 2008, 41, 127-150. [CrossRef] 
120. Jana, A.; Bhattacharya, A.K. Assessment of coastal erosion vulnerability around Midnapur-Balasore Coast, Eastern India using integrated remote sensing and GIS techniques. J. Indian Soc. Remote Sens. 2013, 41, 675-686. [CrossRef]

121. Nguyen, T.T.; Bonetti, J.; Rogers, K.; Woodroffe, C.D. Indicator-based assessment of climate-change impacts on coasts: A review of concepts, methodological approaches and vulnerability indices. Ocean Coast. Manag. 2016, 123, 18-43. [CrossRef]

122. Xing, Y.; Liang, Q.; Wang, G.; Ming, X.; Xia, X. City-scale hydrodynamic modelling of urban flash floods: The issues of scale and resolution. Nat. Hazards 2019, 96, 473-496. [CrossRef]

123. Smith, A.; Sampson, C.; Neal, J.; Bates, P.D.; Trigg, M.; Freer, J.; Porter, R.; Kappes, M.; Simpson, A.; Jongman, B. Modeling and mapping of global flood hazard layers. In Global Flood Hazard: Applications in Modeling, Mapping, and Forecasting, 1st ed.; Schumann, G.J.-P., Bates, P.D., Apel, H., Aronica, G.T., Eds.; American Geophysical Union: Washington, DC, USA, 2018.

124. Van de Sande, B.; Lansen, J.; Hoyng, C. Sensitivity of coastal flood risk assessments to digital elevation models. Water 2012, 4, 568-579. [CrossRef]

125. Small, C.; Sohn, R. Correlation scales of digital elevation models in developed coastal environments. Remote Sens. Environ. 2015, 159, 80-85. [CrossRef]

126. Kulp, S.A.; Strauss, B.H. CoastalDEM: A global coastal digital elevation model improved from SRTM using a neural network. Remote Sens. Environ. 2018, 206, 231-239. [CrossRef]

127. Du, X.; Guo, H.; Fan, X.; Zhu, J.; Yan, Z.; Zhan, Q. Vertical accuracy assessment of freely available digital elevation models over low-lying coastal plains. Int. J. Digit. Earth 2016, 9, 252-271. [CrossRef]

128. Berry, P.A.M.; Smith, R.; Benveniste, J. Altimeter Corrected Elevations, Version 2 (ACE2); NASA Socioeconomic Data and Applications Center (SEDAC): Palisades, NY, USA, 2019.

129. Ramieri, E.; Hartley, A.; Barbanti, A.; Santos, F.D.; Gomes, A.; Hilden, M.; Laihonen, P.; Marinova, N.; Santini, M. Methods for assessing coastal vulnerability to climate change. In ETC CCA Technical Paper; European Environment Agency, European Topic Centre on Climate Change Impacts, Vulnerability, and Adaptation: Bologna, Italy, 2011; Volume 1, pp. 1-93.

130. Retchless, D.P.; Brewer, C.A. Guidance for representing uncertainty on global temperature change maps. Int. J. Climatol. 2016, 36, 1143-1159. [CrossRef]

131. Hyder, A.A.; Corluka, A.; Winch, P.J.; El-Shinnawy, A.; Ghassany, H.; Malekafzali, H.; Lim, M.-K.; Mfutso-Bengo, J.; Segura, E.; Ghaffar, A. National policy-makers speak out: Are researchers giving them what they need? Health Policy Plan. 2011, 26, 73-82. [CrossRef]

132. Aswani, S.; Howard, J.A.E.; Gasalla, M.A.; Jennings, S.; Malherbe, W.; Martins, I.M.; Salim, S.S.; Van Putten, I.E.; Swathilekshmi, P.S.; Narayanakumar, R. An integrated framework for assessing coastal community vulnerability across cultures, oceans and scales. Clim. Dev. 2019, 11, 365-382. [CrossRef]

133. Jones, S. Mapping Coastal Risks and Social Vulnerability: Principles and Considerations; College of William \& Mary Law School: Williamsburg, VA, USA, 2015.

(C) 2020 by the authors. Licensee MDPI, Basel, Switzerland. This article is an open access article distributed under the terms and conditions of the Creative Commons Attribution (CC BY) license (http://creativecommons.org/licenses/by/4.0/). 